\title{
Optical coherence tomography-current technology and applications in clinical and biomedical research
}

Marschall, Sebastian; Sander, Birgit; Mogensen, Mette; Jørgensen, Thomas Martini; Andersen, Peter E.

Published in:

Analytical and Bioanalytical Chemistry

Link to article, DOI:

$10.1007 / \mathrm{s} 00216-011-5008-1$

Publication date:

2011

Link back to DTU Orbit

Citation (APA):

Marschall, S., Sander, B., Mogensen, M., Jørgensen, T. M., \& Andersen, P. E. (2011). Optical coherence tomography - current technology and applications in clinical and biomedical research. Analytical and Bioanalytical Chemistry, 400(9), 2699-2720. https://doi.org/10.1007/s00216-011-5008-1

\section{General rights}

Copyright and moral rights for the publications made accessible in the public portal are retained by the authors and/or other copyright owners and it is a condition of accessing publications that users recognise and abide by the legal requirements associated with these rights.

- Users may download and print one copy of any publication from the public portal for the purpose of private study or research.

- You may not further distribute the material or use it for any profit-making activity or commercial gain

- You may freely distribute the URL identifying the publication in the public portal 


\title{
Optical Coherence Tomography
}

\section{Current technology and applications in clinic and biomedical research}

\author{
Sebastian Marschall • Birgit Sander • Mette Mogensen • \\ Thomas M. Jørgensen • Peter E. Andersen
}

Received: date / Accepted: date

\begin{abstract}
Optical coherence tomography (OCT) is a non-invasive imaging technique providing real-time twoand three-dimensional images of scattering samples with micrometer resolution. Mapping the local reflectivity, OCT visualizes the morphology of the sample. In addition, functional properties such as birefringence, motion or the distribution of certain substances can be detected with high spatial resolution. The main field of application is bio-medical imaging and diagnostics. In ophthalmology, OCT is accepted as a clinical standard for diagnosing and monitoring treatment of a number of retinal diseases, and OCT is becoming an important instrument for clinical cardiology. New applications are emerging in various medical fields, e. g. early-stage cancer detection, surgical guidance, and early diagnosis of musculoskeletal diseases. OCT has also proven its value as a tool for developmental biology. The number of companies involved in manufacturing OCT systems has increased substantially during the last years - especially due to its success in opthalmology - and this technology can be expected to continue to spread into various fields of application.
\end{abstract}

Keywords optical coherence tomography · optical imaging $\cdot$ clinical/biomedical analysis

S. Marschall, T. M. Jørgensen, P. E. Andersen*

DTU Fotonik - Dept. of Photonics Engineering, Technical University of Denmark, P.O. box 49, 4000 Roskilde, Denmark

*Phone: +45 46774555

*E-mail: peta@fotonik.dtu.dk

B. Sander

Dept. of Ophthalmology, Glostrup Hospital, Nordre Ringvej 57, 2600 Glostrup, Denmark

M. Mogensen

Dept. of Dermatology, Gentofte Hospital, Niels Andersens Vej 65, 2900 Hellerup, Denmark

\section{Introduction}

Optical coherence tomography (OCT) has developed rapidly since the first realization in 1991 [1]. For several years, OCT has been commercially available and accepted as a clinical standard within ophthalmology for diagnosis of retinal diseases. Since the commercialization of the first OCT systems by Humphrey Instruments (now owned by Carl Zeiss Meditec) in 1996, the market has rapidly grown. Presently, there are more than 20 system manufacturers and many more suppliers of components and equipment [2]. Recently, the first commercial systems for intravascular imaging in cardiology have entered the market and were approved in the US, Europe and Asia [3,4]. Emerging applications within biology, medicine and various technical fields are continuously explored by many research groups worldwide. In parallel, intense efforts are aiming at technical improvements in terms of imaging speed, resolution, image quality and functional capabilities.

Optical coherence tomography is often described as the optical analogue to ultrasound, as it probes the sample with light instead of sound and maps the reflectivity as a function of depth. It is capable of providing realtime cross-sectional images (Fig. 1), resolving features typically on the order of $10 \mu \mathrm{m}$, but even depth resolution down to $1 \mu \mathrm{m}$ or less is possible [5-7]. The penetration depth into scattering samples is limited; in biologic tissues typically to a few millimeters, which is nevertheless higher than other high-resolution optical techniques, e.g. confocal microscopy [8], can achieve. OCT is comparably inexpensive, capable of real-time imaging, and, using non-ionizing near-infrared light, safe for repeated examinations. Hence, it is a valuable complement to other clinical tomography modalities like ul- 

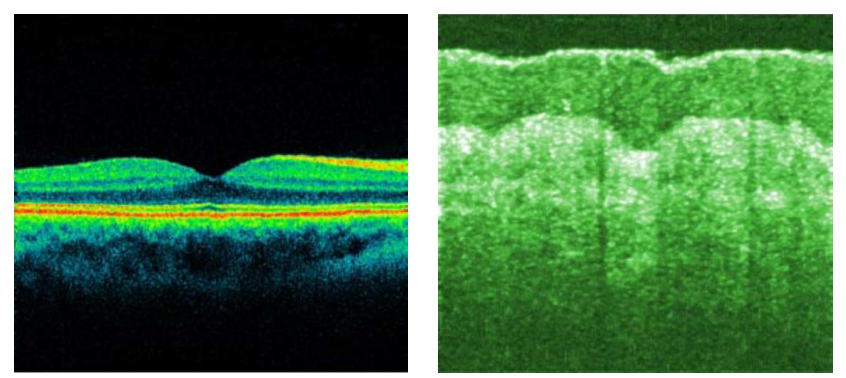

Fig. 1 Cross-sectional OCT images can non-invasively reveal the morphology of biologic samples. Left: scan across the fovea centralis of a human retina. Right: image of human skin at the palmar aspect of the thumb.

trasound imaging, magnetic resonance tomography, or X-ray computed tomography.

In the first part of the present review, we give an introduction into the fundamental principles of OCT imaging, its main functional extensions, and possible additional contrast mechanisms. The following part discusses the applications of OCT, focusing on the main fields within ophthalmology, cardiology, and dermatology and providing an overview over other biomedical and scientific applications. Besides reviewing the current state-of-the-art, we will address new developments and recent trends, e.g. the combination of OCT with other imaging modalities. Technical applications of OCT are not included here, but have been covered comprehensively by Stifter et al. [9]. A detailed discussion of all theoretical aspects related to OCT would be out of scope of this article. Instead, we may refer the reader to the review by Fercher [10] or to the books by Brezinski [11] or Drexler and Fujimoto [12].

\section{Fundamentals}

Optical Coherence Tomography is an interferometric technique that detects reflected or backscattered light from turbid optical media. By utilizing the low time coherence of broadband light sources, OCT creates depthresolved reflectivity profiles of the sample. This section introduces the different implementations of OCT, discusses important system parameters along with the influence of sample properties, and presents possible functional extensions.

\subsection{The principle behind OCT}

OCT measures the depth-resolved reflectivity of scattering materials, by detecting reflected or backscattered light. Every OCT system probes the sample with a beam of light, and lets the reflections interfere with a reference beam originating from the same light source. From the resulting interference signal, one can derive the reflectivity profile along the beam axis. This onedimensional depth scan is called A-scan, in analogy to ultrasound imaging. OCT systems perform many adjacent A-scans in order to create two- or three-dimensional images of the sample.

A-scans can be acquired either in the time domain (TD) or in the frequency domain (FD). TD-OCT systems (Fig. 2) were the first to be implemented [1]. These perform the depth scan based on low coherence interferometry (LCI) which had previously been applied for examining optical fibers [13] or for one-dimensional length measurements of human eyes in vivo [14]. By using light with broad spectral bandwidth and thus low coherence length, only backreflections from the sample with a round-trip path approximately equal to the reference path can interfere with the reference beam. This condition creates a spatial gate as wide as the coherence length of the light that selectively interrogates the backreflection from a certain depth within the sample. This coherence gate is shifted along the probing beam axis by changing the length of the reference path. The resulting light intensity at the interferometer output is then modulated with an amplitude corresponding to the reflectivity profile of the sample. Adjacent structures can be separated in a depth profile if they are further apart than the width of the coherence gate. Thus, the lower the temporal coherence of the probing light is, or the broader the bandwidth, respectively, the higher is the depth resolution.

An FD-OCT system acquires A-scans with a fixed reference path by measuring the spectral response of the interferometer [15]. The information is then encoded as an interferogram in optical frequency space, a sum of oscillations with different periods corresponding to reflections from different depths. A Fourier transform of this interferogram reveals the reflectivity profile of the sample. The same relation between bandwidth and depth resolution as in TD-OCT is also valid for FDOCT.

Two basic approaches exist for implementing FDOCT. One can illuminate the interferometer with broadband light and separate the spectral components with a spectrometer at the output (Fig. 3 a) $[16,17]$. This method is termed Spectral Domain-OCT (SD-OCT). Alternatively, one can probe with different optical frequencies sequentially and measure the power at the output with a single photo detector (Fig. 3 b) [18-20]. A similar principle was applied earlier to examine optical fibers [21,22]. With a tunable narrowband light source, one performs a sweep over a broad range of optical frequencies, which led to the term Swept Source- 


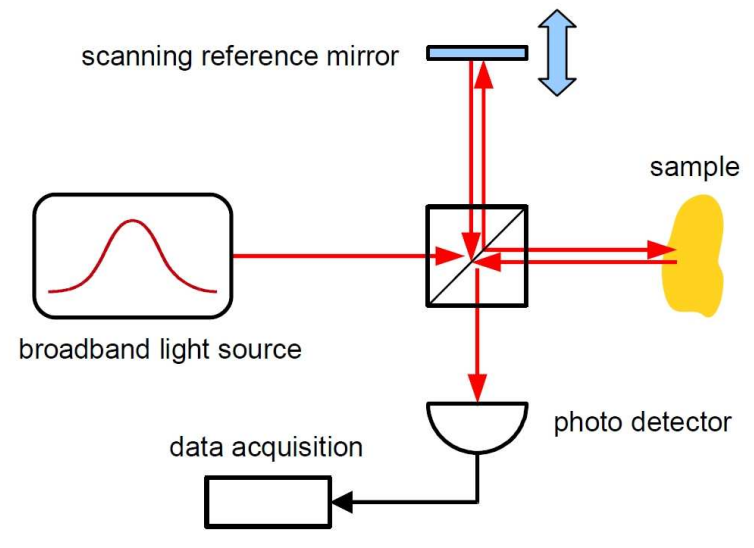

Fig. 2 Typically, an OCT system is based on a Michelson interferometer that directs a fraction of the light to the sample and the remaining part to a reference mirror. The backreflections from both arms interfere on a photo detector. In TD-OCT, the depth scan is performed by translating the reference mirror.

OCT $(\mathrm{SS}-\mathrm{OCT})^{1}$. Typically, a swept source is implemented as an external cavity semiconductor laser with a rapidly tunable filter for frequency selection [23-25]. A special type among these are Fourier domain modelocked (FDML) lasers [26], which enable ultra-high Ascan acquisition rates [27].

In recent years, FD-OCT has become increasingly popular for research and medical applications, due to its significantly higher imaging speed. FD-OCT allows for very high A-scan rates, because it requires no mechanical scanning of the reference path length. This advantage comes, however, at the cost of higher data processing complexity, limited dynamic range [28], signal decrease with the distance of objects from zero (defined by the reference path length), and signal ambiguity for objects above or below zero which may require additional measures for compensation [29-35]. The choice between SD-OCT or SS-OCT depends mainly on the operating wavelength range [36]. For wavelengths below $1 \mu \mathrm{m}$, SD-OCT is favored because silicon-based line cameras with sufficient pixel number and high readout speed are readily available. Higher wavelengths require InGaAs-based cameras which are more expensive and not yet as technologically advanced. However, highperformance swept sources for the $1.3 \mu \mathrm{m}$ range can

1 Throughout the literature, there is no uniform terminology for the OCT embodiments performing the depth scan in the frequency domain. The terms "frequency domainOCT" and "spectral domain-OCT" may be interchanged, or "Fourier domain-OCT" may be used for either one. "Swept source-OCT" is also called "Optical frequency domain imaging", while spectrometer-based OCT was formerly referred to as "Spectral Radar".
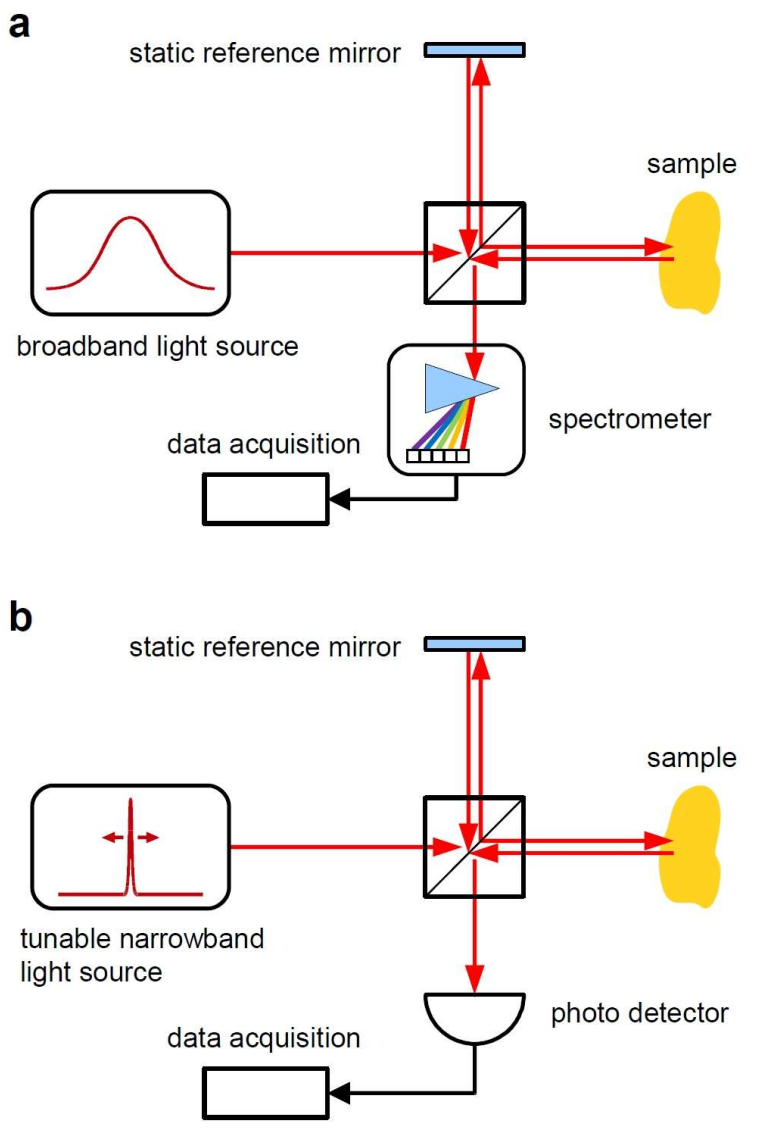

Fig. 3 In FD-OCT, each depth scan is performed by sampling the interference pattern in optical frequency space, either with a spectrometer and a broadband light source (a) or with a photo detector and a tunable narrowband light source (b). In both cases, the reference mirror remains at a fixed position.

be implemented from fiber-optic components developed for telecommunication. Similar components have also become available for the intermediate band between $1 \mu \mathrm{m}$ and $1.1 \mu \mathrm{m}$, although in general with lower performance. Intense research is thus aiming at the development of high-speed tunable lasers with adequate bandwidth and output power for these wavelengths [37, 38]. Considering this, none of the different OCT implementations can be pointed out as being superior. The optimal choice is always dependent on the actual application.

\subsection{Figures of merit}

In the following, we describe the figures of merit important to characterize an OCT system or to compare OCT with other imaging techniques. The main strength of OCT is the depth resolution or axial resolution which 
is linked to the light source spectrum. For a Gaussian spectrum with center wavelength $\lambda_{c}$ and $3 \mathrm{~dB}$-bandwidth $\Delta \lambda$, the axial resolution in air is

$\delta z=\frac{2 \ln 2}{\pi} \frac{\lambda_{c}^{2}}{\Delta \lambda} \approx 0.44 \frac{\lambda_{c}^{2}}{\Delta \lambda}$.

In a medium of refractive index $n$, the resolution becomes $\delta z / n$. With typical light sources, for instance superluminescent diodes (SLD), a resolution around 5 $10 \mu \mathrm{m}$ in tissue $(n \approx 1.4)$ is possible, while ultra broadband light sources, e. g. supercontinuum sources, enable a resolution down to $1 \mu \mathrm{m}[5,6]$.

Most optical microscopy techniques, such as confocal microscopy [8], achieve high resolution with a high numerical aperture (NA) objective. In contrast, OCT gains axial resolution from the coherence gate. Hence, one uses typically a low NA objective that provides a long depth of focus covering the entire imaging depth range. The transverse resolution, however, is then only moderate (several $10 \mu \mathrm{m}$ ). A number of techniques have been developed that enable imaging with a high NA to provide high transverse resolution while maintaining a long imaging depth range. TD-OCT allows for dynamic focusing, i. e. during each A-scan, the sharp focus can be shifted through the sample synchronously with the coherence gate. In FD-OCT, several images acquired at the same site with different focal planes can be compounded, allowing to focus tightly while maintaining an adequate overall depth of focus [39]. Both in time and frequency domain, one can implement optical coherence microscopy (OCM), where so-called en-face images are acquired in a plane transverse to the probing beam [40]. OCM combines the high spatial resolution of confocal microscopy with the depth-selective coherence gate of OCT.

While OCT has a high depth resolution, the penetration depth into typical biologic samples is usually limited to a few millimeters. Still, OCT is not only useful for examining the outer body surface, because endoscope probes [41] or subcutaneous imaging needles [42] give access to hollow organs and selected sampling volumes in soft tissue. Hence, OCT is a versatile modality complementing other clinical imaging techniques (Fig. 4).

The sensitivity of an OCT system is a measure how small a fraction of the probing light is detectable as signal above the noise floor. High sensitivity is important for deep penetration into scattering samples. It mostly depends on detection efficiency and noise sources present in the system. Most OCT systems achieve sensitivities in the range of $90-100 \mathrm{~dB}$.

The imaging speed is given by the A-scan acquisition rate and therefore limited by the reference path scanning velocity in TD-OCT, the camera read-out rate in

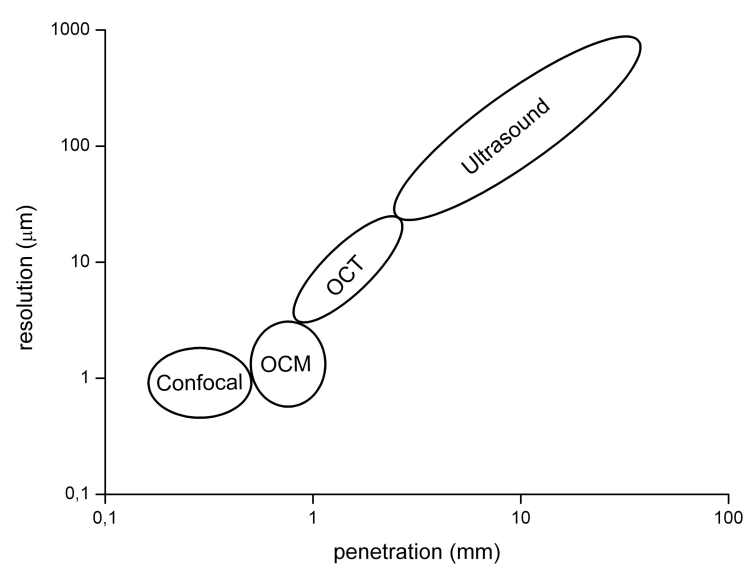

Fig. 4 OCT and OCM close the gap between high resolution optical microscopy techniques (e.g. confocal microscopy) and techniques with long penetration depth (e.g. ultrasound imaging).

SD-OCT, or the sweep rate of the light source in SSOCT. Fast image acquisition is important for sampling large volumes - especially for in vivo imaging where sample motion cannot be avoided [43] — and it opens the possibility to observe dynamic phenomena temporally resolved $[44,45]$. Typical state-of-the-art research systems feature A-scan rates up to several hundreds of kilohertz. The fastest high-quality imaging reported so far was demonstrated in an SS-OCT system performing 20.8 million A-scans per second [27].

\subsection{Optical properties of the sample}

Apart from the hardware parameters, the performance of OCT imaging is also influenced by sample properties. Absorption and scattering attenuate the signal, thereby reducing the penetration depth [46]. A mismatch of chromatic dispersion in the sample and the reference path leads to a degradation of axial resolution, and should be compensated by inserting dispersive elements into the reference arm [47] or by signal-processing [48].

In biologic tissue, the maximum imaging depth is limited by strong scattering [49]. Scattering arises from variations in the index of refraction between different tissue constituents and the surrounding medium. It is dependent on the size and shape of present scatterers, hence the macroscopic scattering properties of different tissue types can vary considerably. Absorption can mostly be avoided by an appropriate choice of the wavelength band. Between $600 \mathrm{~nm}$ and $1300 \mathrm{~nm}$, the absorption of water and other typical tissue constituents like melanin or hemoglobin is low (Fig. 5) and forms an 
optical window [50]. The choice of the operating wavelength within this window depends on the requirements of the application. Light at $1300 \mathrm{~nm}$ allows for deep penetration into most tissues, like skin or mucosa, because absorption in melanin and scattering decrease with increasing wavelength [49]. Longer wavelengths, e. g. around $1700 \mathrm{~nm}$, may enable even deeper penetration for applications where water absorption has no significant influence [51]. However, these long wavelengths are not suited for probing the posterior eye segment in vivo due to strong signal attenuation in the vitreous which mainly consists of water. Hence, the $800 \mathrm{~nm}$ range exhibiting very low water absorption is commonly used for retinal imaging [52]. For deep penetration into the subretinal layers, the $1050 \mathrm{~nm}$ band provides the best trade-off between these factors [52], while at the same time featuring minimal chromatic dispersion in water [53].

A phenomenon observed when imaging highly scattering samples, like most biologic tissues, is speckle. The speckle pattern, appearing as a grainy fine structure in OCT images, is caused by interference of light reflected from many randomly distributed scatterers within the probing volume [54]. Speckle characteristics, such as the size and the intensity distribution can provide additional information about the underlying scatterers [55, 56]. However, the speckle texture obscures small features in the image and is usually considered a source of noise. Numerous speckle reduction methods have therefore been developed and applied to OCT [54]. Some are based on incoherent addition of several signals from the same location under varying conditions, e.g. angular compounding [57], spatial compounding [58,59], and frequency compounding [60]. Where compounding is not feasible different image processing techniques can be applied to suppress speckle, e.g. various types of smoothing filters, deconvolution $[61,62]$, wavelet analysis [63], rotating kernel transformation [64], and anisotropic diffusion [65].

\subsection{Functional imaging with OCT}

In addition to structural images representing the morphology of the sample, one can extract functional information from the OCT signal. Functional OCT includes the detection of polarization properties, local flow of liquid, chemical composition or optical and mechanical properties of the sample. It can provide valuable information not contained in the structural image.

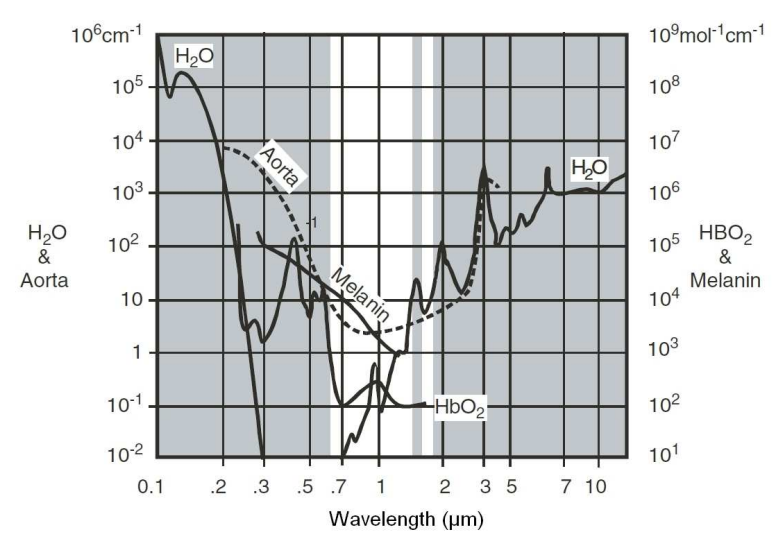

Fig. 5 Absorption spectra of typical tissue constituents (water $\left(\mathrm{H}_{2} \mathrm{O}\right)$, oxyhemoglobin $\left(\mathrm{HbO}_{2}\right)$, melanin) and aortic tissue (dashed curve). The wavelength band between 0.6 and $1.3 \mu \mathrm{m}$ is well suited for optical imaging, due to relatively low overall absorption. The ranges with bright background have been used for OCT. Printed with permission [66]

\subsubsection{Polarization sensitive OCT}

Polarization sensitive OCT (PS-OCT) takes advantage of the polarization information carried by the light backscattered from the sample $[67,68]$. Tissue can change the polarization state of the light by several mechanisms: birefringence [69], diattenuation [70], or polarization scrambling [71]. While early implementations of PS-OCT measured only reflectivity and phase retardation between the polarization axes $[67,68]$, improved techniques developed in recent years can extract and image more information, such as Stokes vectors of the backscattered light [72], Müller and Jones matrix distribution [73,74], axis orientation [75], and diattenuation [70]. If diattenuation is neglected - it is very low in most biological tissues - the three most important parameters, reflectivity, retardation, and axis orientation (Fig. $6 \mathrm{a}-\mathrm{c}$ ) can be determined by a phase sensitive twochannel method that requires only a single measurement per sample location [75]. Other quantities can be derived from the acquired data, e. g. the degree of polarization uniformity (Fig. $6 \mathrm{~d}$ ) that reveals how well a certain volume of the sample preserves the polarization of the probing light [76].

Whereas early versions of PS-OCT were based on the time domain A-scan technique, FD-OCT has now become the preferred data acquisition method. The first spectral domain systems were developed in 2002 [77], and since 2008 also swept sources are in use [78,79]. The implementation PS-OCT in fiber optics is challenging, because standard optical fibers introduce birefringence and cross-talk between the polarization axes. Nevertheless, since 2000, different fiber-based setups allowing for 

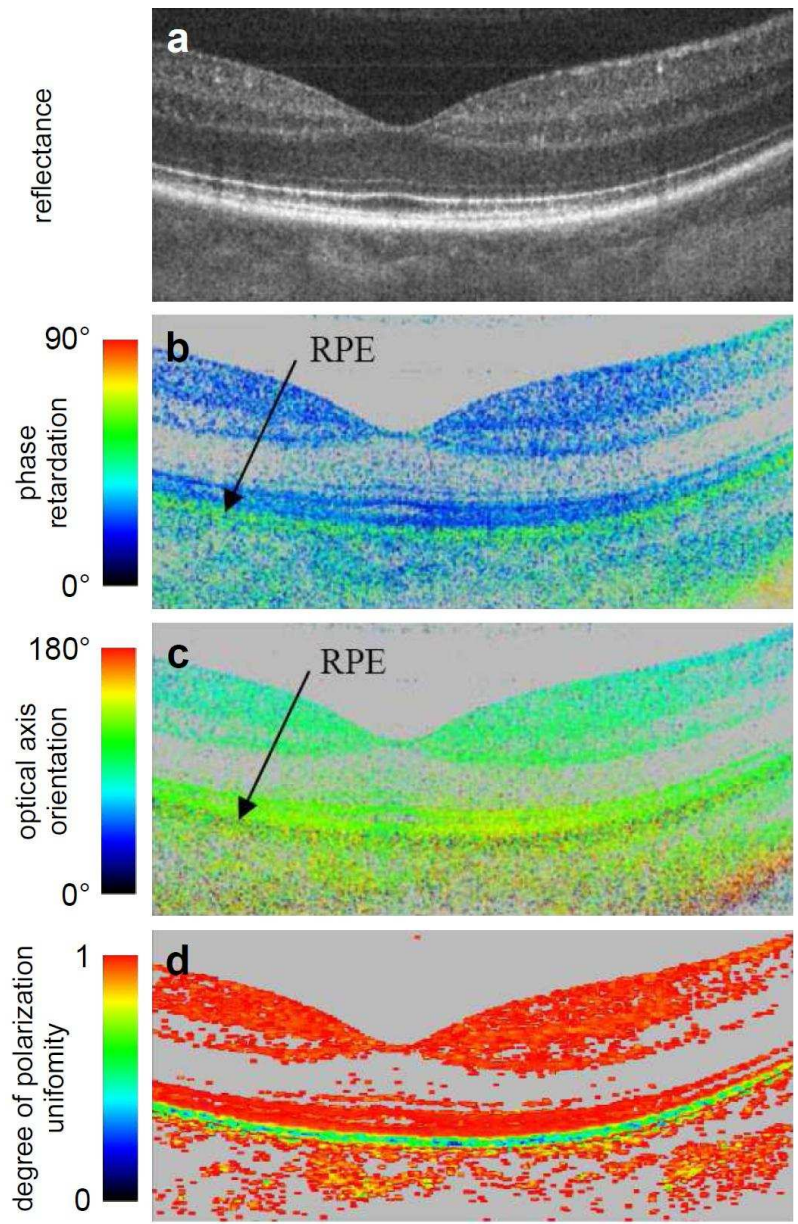

Fig. 6 Cross-sectional OCT image of a human retina across the fovea centralis. In addition to providing structural reflectance images (a), polarization sensitive OCT can map quantities such as the phase retardation between the polarization axes (b) or the optical axis orientation (c). The degree of polarization uniformity $(\mathrm{d})$ derived from the measured data quantifies how well the sample volume preserves the polarization. It may be used to delineate the strongly depolarizing retinal pigment epithelium (RPE). Printed with permission [76].

polarization sensitive imaging were designed [80-83]. In addition to the embodiments that measure the absolute polarization state of the light, there is a less complex approach to determine relative birefringence in a sample $[83,84]$. It is very robust against artifacts introduced by rotating catheter probes or birefringence in bent delivery fibers [85] which is advantageous especially for endoscopic applications. These developments enabling ultra-high imaging speed and flexible, alignment-free setups make polarization sensitive imaging feasible for clinical applications.

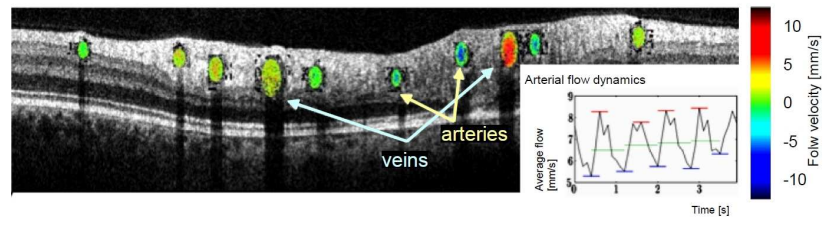

Fig. 7 Circular Doppler-OCT scan around the optic nerve head in a human retina. Structural data are displayed as grayscale image, and the flow velocity profile in the retinal blood vessels is overlaid in color. The inset plot shows the timeresolved arterial blood flow velocity averaged over the vessel area. Courtesy of Prof. R. Leitgeb, Medical University of Vienna, Austria.

\subsubsection{Doppler OCT}

By analyzing the OCT signal, one can extract the Doppler shift of the backscattered light caused, for instance, by blood flow in tissue (Fig. 7). The first Doppler OCT (DOCT) systems implemented by Izatt et al. [86] and Chen et al. [87] in 1996 acquired the velocity distribution by performing short-time Fourier transforms on a single A-scan. This method suffers from an inevitable trade-off between velocity sensitivity, axial resolution and imaging speed, which renders real-time imaging of blood flow in small capillaries impossible. A new method introduced in 2000 by Zhao et al. derives the velocity from the phase difference between two subsequent A-scans [88]. It allows for high-resolution realtime Doppler imaging while maintaining submillimeter per second velocity sensitivity.

DOCT with frequency domain data acquisition has the advantage that it requires no moving parts in the interferometer that could cause jitter as in a TD-OCT system. Leitgeb et al. demonstrated in 2002 a spectral domain DOCT system that allowed for high-speed imaging with high phase stability and thus a large range of detectable velocities [89]. In 2005, Vakoc et al. implemented DOCT with a swept source system [90], and Adler et al. proved in 2007 that Fourier domain modelocked lasers with their high phase-stability are perfectly suited as light source for velocity and phase measurements at ultrahigh speed [91].

\subsubsection{Phase sensitive OCT}

By analyzing the phase of an OCT signal, one can detect very small changes of the optical path length of the reflected light, down to a few nanometers [47]. This method enables very precise measurements of the thickness profile or changes in the thickness of transparent specimen, e.g. cell cultures or thin material samples [92-94]. It requires a system with very high phase stability, which is normally not given, because interfero- 
meters are subject to phase fluctuations introduced by vibrations, air currents, and thermal drift. A number of techniques have been developed to compensate for these influences.

Differential phase OCT systems gain contrast from the phase difference between two signals from different probing volumes. Various embodiments can measure phase variations between adjacent lateral positions [95, $96]$, between a narrow spot and the surrounding area [93], or between reflections from different depths within the sample [97]. The light of both channels travels along the same path in the interferometer, so that phase fluctuations cancel out after subtraction. Typically, the signals can be separated by using orthogonal polarization states in the two channels, which requires that the sample does not alter the polarization state of the probing light.

Other approaches employ a standard interferometer where an additional coherent laser beam at a different wavelength travels the same path as the probing light. The interference signal of this beam provides a reference for computational phase noise cancellation [92] or for active stabilization of the interferometer [98].

The development of FD-OCT enabled the application of common path interferometers, where a partial reflection in the probing beam path is used as reference $[94,99]$. Typically, a cover slip in front of the sample serves as reference mirror. These interferometers are very simple and feature the same passive phase stability as the polarization-based differential phase systems.

\subsubsection{OCT elastography}

OCT is not only capable to image structural morphology, it can also detect microscopic displacements or motion within a sample. In conjunction with the controlled application of stress (force per unit area) or vibrations, one can thus determine the spatially resolved elasticity of a specimen. There are several approaches commonly referred to as OCT elastography or optical coherence elastography (OCE). The early work is based on tracking the local displacement in the speckle pattern when constant stress is applied [100102], which reveals spatial changes in elastic modulus of the sample. This method is computationally intensive and limited to displacements small enough to keep the two speckle patterns sufficiently correlated. As an alternative, it has been proposed to detect the axial shift between adjacent A-scans resulting from oscillating stress applied synchronously with the A-scan rate [103]. Another embodiment of OCE detects the Doppler shift arising from mechanical vibrations that are excited in the material [104-106]. A recently developed detec- tion scheme enables the characterization of the sample response over a wide range of vibration frequencies up into the kilohertz-regime $[107,108]$.

A number of experimental studies on ex vivo specimen demonstrated the potential of OCT elastography to quantify the elasticity of biologic tissue $[100,102$, 106]. However, in vivo measurements require a method to apply uniform stress in a controlled manner, which is challenging especially for intra-vascular measurements [102]. First in vivo experiments have recently been conducted on human skin $[107,109,110]$.

\subsubsection{Molecular contrast}

A number of extensions to OCT can extract chemical information from the sample, i. e. map the spatial distribution of certain substances. The variety is so wide, that we can only present some prominent examples in this place. Detailed discussions can be found in the reviews of Yang [111] and Boppart et al. [112], respectively.

Since OCT is based on broadband light sources, it can be used to detect the absorption features of molecules that fall within the light source spectrum, as demonstrated by Morgner et al. in 2000 [113]. However, in the near-infrared (NIR) region, constituents of biologic tissue exhibit mostly elastic scattering rather than absorption [49]. Probably the most interesting molecule is hemoglobin, and spectroscopic OCT (SOCT) was suggested as a means to assess the oxygen saturation level in blood [114]. However, practical difficulties of SOCT limit the applications. The measured attenuation spectra are not only given by absorption, also by scattering, and the separation of both contributions requires considerable effort $[115,116]$. Furthermore, SOCT brings an inherent trade-off between spatial and spectral resolution. In a simplified approach, the concentration of known substances can be determined by comparing the signal attenuation in different wavelength bands $[117,118]$.

Specific contrast for different types of tissue or the chemical composition can also be gained by utilizing coherent non-linear effects in OCT [119]. Second harmonic generation (SHG), or frequency-doubling, does not occur in uniform, isotropic media and provides therefore specificity for anisotropic or birefringent structures, such as collagen layers $[120,121]$. With coherent anti-Stokes Raman scattering (CARS), one can identify substances by the frequency spectra of their molecular bond vibrational states [122].

Even though most OCT applications are based on endogenous contrast mechanisms, it is also possible to apply exogenous contrast agents to gain enhanced or 
specific contrast. NIR dyes with characteristic absorption spectra can be useful in conjunction with a spectroscopic OCT technique [123]. Another way of using dyes is the pump-probe technique, which provides contrast based on the variation in absorption when the dye molecules are excited by a pump light source [124]. A number of other contrast agents have been studied which rely on enhanced scattering to increase the OCT signal locally. Among these are microbubbles [125], engineered microspheres [126], and different types of plasmon-resonant gold nanoparticles $[127,128]$. Exogenous contrast agents may be used to increase the contrast between blood vessel and the surrounding tissue [125], some have an inherent selectivity to accumulate in certain types of tissue, and many offer the possibility to be targeted to specific markers [123], e. g. receptors that are expressed on diseased or cancerous cells [129]. Therefore, exogenous contrast can eventually become a valuable additional tool for OCT in medical diagnostics or biologic research.

\subsubsection{Measurement of bulk optical properties}

In addition to providing structural information, intensity-based depth profiles offer the possibility to extract optical properties, such as the refractive index or the coefficients of scattering and attenuation. Considerable effort went into theoretical models to analyze the OCT data. However, the heterogenity of biologic tissues renders the exact spatially resolved determination of optical properties often unfeasibly complicated, so that rather average values for certain sample volumes are calculated.

In 1995, Tearney et al. presented two procedures to measure the refractive index as an averaged bulk property using OCT [130]. Knüttel et al. expanded Tearney's focus tracking method to measure depth-resolved changes of the refractive index [131]. Based on the model by Thrane et al. relating the OCT signal strength to scattering [132], Letvitz et al. extracted the scattering coefficient and the effective anisotropy factor from OCT A-scans [133], and Turchin et al. developed an algorithm to derive the scattering coefficients of multi-layer samples [134]. Both methods aimed for the characterization of different pathologic states in tissue samples. These models are based on the assumption that the absorption coefficient is very low compared to the scattering coefficient, otherwise their contributions to the signal attenuation cannot be separated, easily. However, the total attenuation coefficient can also contain sufficient information for diagnostic purposes [135-138].

\section{Applications}

OCT has found manifold applications in medicine, biology and also a variety of technical applications. The main field of application is ophthalmology, where OCT has now been accepted as a clinical standard. A similar development is currently ongoing in cardiology, where the first commercial intravascular OCT systems have found approval for clinical use. The value of OCT for diagnosing diseases or monitoring treatment in various other fields is subject of continued research.

In this section, we present applications of OCT in the clinical environment and give an outlook on technical developments which may improve the diagnostic capabilities in the near future. We will cover the main fields and provide an overview over other areas of clinical research using OCT.

\subsection{Ophthalmology}

In ophthalmology, OCT has been used to perform direct imaging of the ocular structure in the anterior and posterior segments of human eyes in vitro and in vivo [139141]. OCT yields a cross-sectional image of the retina with a resolution comparable to a histological section in light microscopy [142] and visualizes retinal structures inaccessible with any other techniques (Fig. 8). OCT is non-invasive, as opposed to fluorescein angiography, and requires no physical contact to the eye like ultrasound imaging which would cause considerable discomfort to the patient. These advantages led to the rapid success in ophthalmology.

OCT is the clinical standard for a number of retinal diseases and is increasingly being used for diagnosis, monitoring and treatment control of vitreoretinal traction and macular holes [143], age related macular degeneration [144], glaucoma [145] and diabetic retinopathy $[146,147]$. Recent reviews giving comprehensive description of ophthalmic OCT were published by van Velthoven et al. [148] and Drexler and Fujimoto [149].

The first commercial OCT system for ophthalmic use was introduced to the market in 1996 (Humphrey Instruments, later acquired by Carl Zeiss Meditec) and in the following years the next generations of systems were released with improved resolution, speed and software. Nearly 10,000 systems have been sold by Carl Zeiss Meditec until 2008 [150] and more manufacturers have entered the market. Today OCT is used in larger clinics but the trend is a spread into smaller clinics as well. 


\subsubsection{OCT in ophthalmic diagnostics}

OCT is used within research and clinic on daily basis. Both visualization of retinal morphology and measurement of retinal thickness have become important to evaluate patients with wet age related macular degeneration. Without treatment, this condition leads rapidly to a substantial loss of vision. It can be treated with vascular endothelium growth factor inhibitors (VEGF inhibitors), which is repeated every month until the disease is inactive $[151,152]$. As the treatment requires an intravitreal injection into the eye, the number of re-treatments should be as low as possible. The decision for retreatment is primarily based on presence of intraretinal or subretinal fluid and the related retinal thickness, and major hospital clinics use OCT for the assessment.

Retinal thickening is also frequent in diabetic retinopathy, both type 1 and type 2 patients, where approximately $15 \%$ develops macular edema. The edema develops slowly and the patient might be unaware for a long time. Treatment is necessary if the edema is large or close to the fovea, i. e. the center of the retina which is the spot of maximal visual acuity. OCT has become a standard instrument for clinical studies exploring treatments of edema, in particular the use of intravitreal injections of steroid and VEGF inhibitors. Blood-glucose and blood-pressure are major risk factors for progressing of diabetic retinopathy and OCT has been used to study the relation between acute changes in bloodglucose, retinal thickness and blood-pressure [153]. The visualization of the pattern of fluid accumulation may be an important tool for detecting patients with more severe stages $[146,147]$. Most likely, OCT will not completely replace invasive methods such as fluorescein angiography but may reduce their application and thus decrease the burden of repeated eye examinations for patients and clinics [144,154].

A third leading cause of visual impairment is glaucoma, a disease with atrophy of the retinal nerve fibers. The diagnosis of glaucoma in early stages is difficult and is based on visual fields defects, i. e. the diagnosis is made when damage has already occurred. Recent studies have shown that OCT can detect the thinning of the retinal nerve fiber layer which typically precedes the loss of visual field $[145,155,156]$. With continuing improvement of resolution and speed, OCT will likely become a valuable tool for early stage glaucoma detection. Numerous studies are currently conducted to evaluate the diagnostic power of new commercially available OCT systems $[157,158]$.

In addition to the major diseases, OCT is used in nearly all fields of eye diseases, such as monitoring and

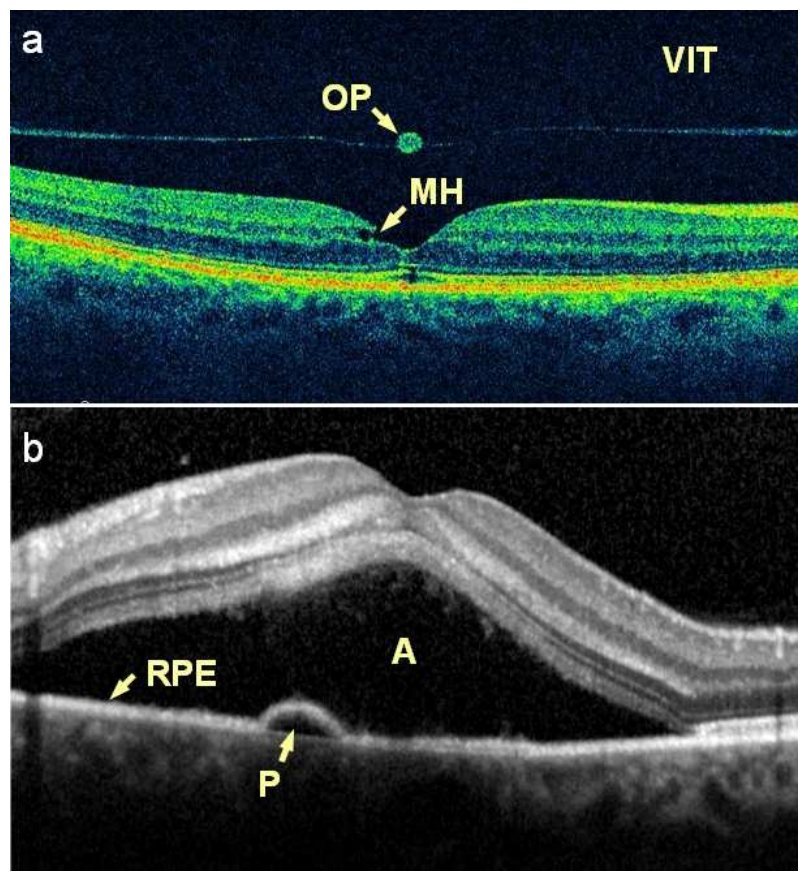

Fig. 8 OCT images of diseased human retinas. (a) A macular hole $(\mathrm{MH})$ has developed after detachment of the vitreous humour from the retina. The OCT image shows clearly the posterior surface of the vitreous (VIT) and reveals the presence of an operculum (OP). (b) Central serous chorioretinopathy has led to a large fluid accumulation anterior (A) and a smaller one posterior $(\mathrm{P})$ to the retinal pigment epithelium (RPE).

follow-up for eye surgery, macular holes, vascular occlusions and examination of the anterior segment of the eye [143, 159-161].

\subsubsection{Developments in ophthalmic OCT}

Clinical OCT applications have until now been based on structural images. However, functional imaging offers many possibilities to acquire additional information that helps to detect diseases. Polarization sensitive OCT enables quantitative measurements of the birefringence of the retinal nerve fiber layer [162]. Detecting changes caused by early stage glaucoma can improve the diagnostic accuracy. PS-OCT is also useful for a more precise delineation of different retinal layers based on their polarization properties $[71,163]$. For instance, the retinal pigment epithelium can be identified by its depolarizing nature, which may prove helpful for the detection and monitoring of diseases affecting this layer [164]. Doppler OCT can visualize blood flow in retinal vessels [165]. In conjunction with fast 3D imaging a new technique for non-invasive angiography can be implemented [166] that could improve diagnosis and 
monitoring of a number of diseases, such as glaucoma, and diabetic retinopathy.

OCT is capable of tracking small changes in the reflectivity of retinal layers that occur in response to an optical stimulus with high spatial and temporal resolution. Compared to other techniques like electro-retinography, OCT provides uncomplicated, non-invasive access for studying the retinal physiology, and may open new possibilities to investigate retinal pathologies [44, 167 .

High transverse resolution in retinal imaging is difficult to achieve due to ocular aberrations. These aberrations can, to a certain extent, be compensated with adaptive optics, enabling transverse resolutions of a few micrometers and an improved signal-to-noise ratio [168, 169].

Light in the $800 \mathrm{~nm}$ range enables ultrahigh resolution imaging of the retina [170]. However, it can hardly penetrate the strongly absorbing retinal pigment epithelium and is therefore less feasible for deep penetration into the choroid beneath the retina. Imaging at $1300 \mathrm{~nm}$ suffers from strong water absorption in the vitreous. For this special purpose, the $1050 \mathrm{~nm}$ band is interesting, since it exhibits a local minimum of absorption and vanishing chromatic dispersion in water. Since Považay et al. demonstrated the potential for deep penetration into the choroid in 2003 [52], a growing number of studies makes use of the $1050 \mathrm{~nm}$ range $[171,172]$. Depending on the diagnostic value of choroid images, $1050 \mathrm{~nm}$ OCT may become an additional standard tool for ophthalmology.

High data acquisition speed is important for in vivo imaging to avoid motion artifacts [43], especially since the eye is constantly moving [45]. It is also the key to imaging large comprehensive $3 \mathrm{D}$ volumes [173] or to the time-resolved observation of dynamic processes $[44,45$, 167]. The recent commercialization of high speed line cameras and swept sources will therefore be an important factor driving the development of the next generation of OCT systems.

\subsection{Cardiology}

Cardiovascular diseases are the leading cause of death worldwide, causing millions of deaths every year [174]. Therefore, early detection of vulnerable atherosclerotic plaques, the most prevalent condition leading to myocardial infarctions, is highly relevant. Characteristic for vulnerable plaques are a thin fibrous cap $(<65 \mu \mathrm{m})$ overlying a lipid pool and infiltrating macrophages [175]. Previously, intravascular ultrasound imaging (IV-US) has been used to visualize plaque lesions, but the re-
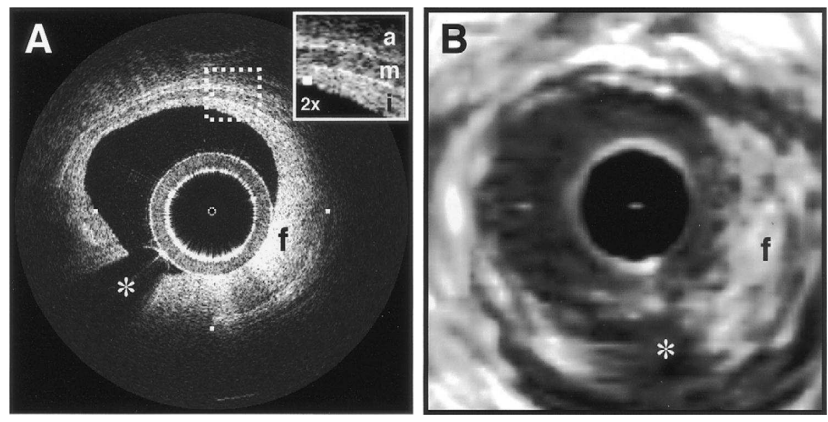

Fig. 9 Images acquired with intravascular OCT (a) and $30 \mathrm{MHz}$ ultrasound (b) in comparison. Due to its higher resolution, OCT has a clear advantage in visualizing the structural details of the vessel walls. i: intimia with intimial hyperplasia, m: media, a: adventitia, f: fibrous plaque, asterisk: guidewire shadow. Printed with permission [176].

solution is not sufficient to make a reliable characterization [176]. Intravascular OCT (IV-OCT) can resolve significantly smaller details (Fig. 9), and has therefore the potential to become an important instrument for the classification of atherosclerotic plaques [177].

Ex vivo measurements demonstrated the ability to distinguish different tissue structures [49] and plaque types $[133,178]$, followed by in vivo studies aiming at the identification of vulnerable atherosclerotic plaques [179-181]. OCT can quantify typical characteristics such as the fibrous cap thickness [182], presence of lipid [135], or macrophage infiltration [183]. The degradation of organized collagen fibers can be detected with PS-OCT $[84,184]$, and extraction of local attenuation coefficients enables the automated identification of different tissue structures [137]. With these capabilities of highresolution intravascular imaging and extraction of information about the tissue composition, OCT has become a valuable research tool for studying cardiovascular diseases [185-187] and possible treatments [188].

Whereas the classification of atherosclerotic plaques is subject of ongoing research, the main clinical application of IV-OCT is monitoring and follow-up of percutaneous coronary interventions [189], especially the deployment of coronary stents [190]. When a stent is implanted, all stent struts should be well apposed to the vessel wall (Fig. 10) and in the subsequent healing process covered by a layer of neointimal tissue. Incomplete stent apposition and lack of neointimal coverage are suspected to increase the risk of possibly fatal late stent thrombosis $[191,192]$. IV-OCT is feasible for longterm follow-up in order to reveal the outcome of stent deployment [193], and as comparative studies show, its superior resolution brings a strong advantage over IVUS [189, 192,194]. 

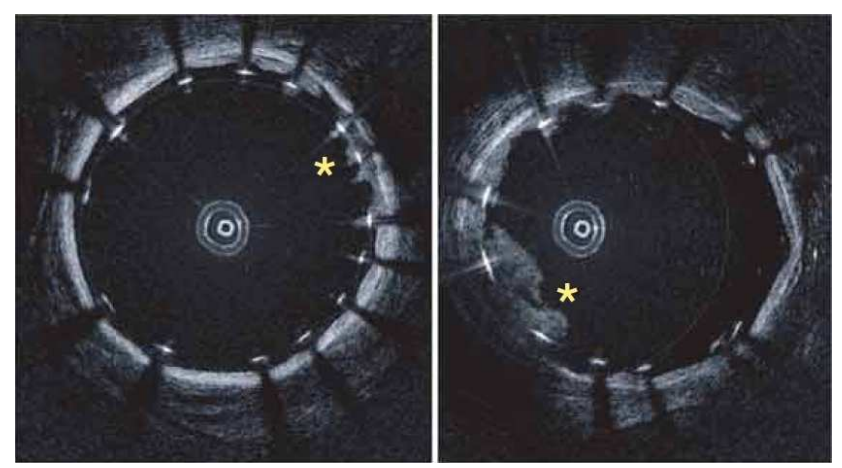

Fig. 10 OCT images of a stented porcine coronary artery in vivo. The stent struts appear as highly reflective objects casting radial shadows. The images reveal tissue prolapses between the struts (asterisks). Printed with permission [195].

The major challenge for in vivo IV-OCT imaging was to overcome the opacity of blood for near-infrared light, arising from scattering by the red blood cells. Clearing the blood vessel for a short time span by saline flushing was successfully demonstrated in animals [196] and humans [176], and has now become common practice. First patient studies indicate the general safety of this method $[197,198]$. Nevertheless, research continues to eliminate the risk of ischemia completely, for instance by matching the refractive index of the blood serum with that of the red blood cells [199] or by using oxygen-carrying flushing liquids [200,201]. An important step was the introduction of high-speed FD-OCT systems, since it enabled the acquisition of large sampling volumes during relatively short flushing periods $[36,195]$.

IV-OCT technology has matured so far that largescale commercialization may be expected in the next few years. Lightlab Imaging (subsidiary of St. Jude Medical) has been selling TD-OCT systems for several years, and recently received approval of their newest intravascular FD-OCT systems in the US, Europe and Asia [3]. Their competitor Volcano Corporation also received clearance for the European market and is working towards the commercial release of their IV-OCT products [4]. Detailed reviews on the current status of technical development and clinical applications are available from Prati et al. [202] and Suter et al. [203].

\subsection{Dermatology}

Because skin is the most easily accessible part of the human body, the potential of OCT as instrument for dermatology was investigated from the onset. OCT appeared promising for examining skin abnormalities, especially those that are difficult to assess by visual in-
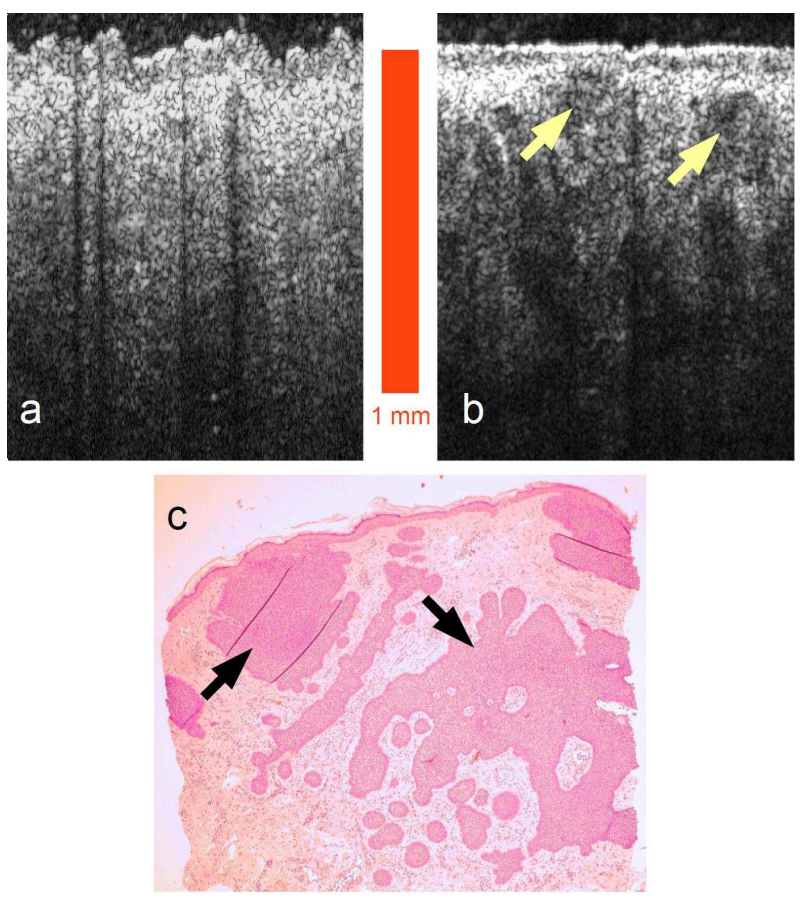

Fig. 11 OCT images of normal skin (a) and basal cell carcinoma (b) show a clear structural difference. The basaloid carcinoma cell islands, main features in the corresponding histological image (c), can also be recognized in the OCT image (arrows).

spection. Hence, most research on OCT in the area of dermatology has addressed non-melanoma skin cancer (NMSC), although OCT has also been studied in relation to photo-damage, burns and inflammatory diseases like psoriasis and eczema $[204,205]$. NMSC includes keratinocyte carcinomas, the most prevalent cancer type in humans, and some more rare skin cancers. In NMSC diagnosis, OCT can potentially reduce the number of invasive skin biopsies, assist in finding an optimal location for a biopsy or measure tumor thickness [206]. However, despite many promising initial results in research, OCT has not yet been established in clinical dermatology.

OCT images reveal the layered structure of the upper part of the skin. In normal skin (Fig. $11 \mathrm{a}$ ), usually a clear boundary between stratum corneum and the living part of the epidermis can be seen, and the epidermis can be distinguished from the dermis in OCT images $[207,208]$. Because OCT is typically not capable of resolving single cells, diagnosing diseases must rely on a change in the skin morphology (Fig. 11 b), such as a break up of tissue layers, general disordered structure or change in amount of backscattered light compared to normal skin $[207,209]$. For instance, OCT can visualize loss of normal skin architecture in malig- 
nant melanomas, which could be used to differentiate them from benign melanocytic nevi [210].

The differentiation between benign and malignant lesions in a clinical setting is considerably more challenging because benign lesions often show the same structure in OCT images as malignant ones. Furthermore, variations with age, skin type, anatomical site etc. must be taken into account [207,211]. Many studies have, however, reported high correlation between OCT images and histology, suggesting that OCT can be used to recognize NMSC lesions [212-214].

In most of the cited studies, decisions were subjective, because they were based on visual inspection of the OCT images. Therefore, the feasibility of machine learning tools was investigated in several studies [215, 216]. Higher diagnostic accuracy compared to human observers could be achieved in some cases, demonstrating the potential as well as the need for improvement of these methods. Better image quality, for instance with speckle reduction [217], could help to extract the relevant features with higher accuracy.

Functional OCT can provide additional information that may be used to locate and characterize skin cancer. The highly organized structure of collagen fibers in the dermis resulting in birefringence breaks down in skin cancer lesions. Distinguishing normal skin and basal cell carcinoma may be possible using PS-OCT, as a pilot study by Strasswimmer et al. concluded [218]. However, in a recent study by Mogensen et al. conducted on more than 100 patients with different types of lesions, PS-OCT could not improve the diagnostic acurracy compare to the assessment based on structural OCT images [219].

Despite promising initial results, OCT could not yet provide improved accuracy in dermatologic diagnostics. Especially the limited penetration depth prevented a significant improvement of diagnostic accuracy. Nevertheless, as technology is further developed, the evaluation of the diagnostic potential is continued, not only on scientific but also commercial basis. Michelson Diagnostics, manufacturer of the first OCT system for skin imaging approved in the US and Europe [220,221], is involved in numerous clinical trials on the assessment of skin cancer and plans to expand these activities in 2011 [222].

\subsection{Emerging medical applications}

Numerous other possible applications of OCT in the medical field have been investigated for their potential in the clinical environment. OCT is promising in many fields of cancer diagnosis, especially where excisional biopsy or another invasive method is typically used but undesirable [223]. OCT is endoscope-compatible [41] and thus well suited to examine hollow organs like the gastrointestinal tract [224-226], the bronchi [227] and the urinary bladder [228]. Subcutaneous imaging needles [42,229, 230] and forward imaging probes [231-233] provide further possibilities to apply OCT for minimally invasive examination. For instance, arthroscopic OCT is a promising instrument for early diagnosis of osteoarthritis $[180,234,233]$ or for the assessment of meniscal pathology [235].

Besides diagnosis, OCT is also useful for guiding or monitoring surgery. One promising application lies in the resection of metastatic lymph nodes in breast cancer patients. Nowadays, often significantly more lymph nodes than necessary are removed, because assessment is only done post-operative via histopathology. By examining the morphology and the optical properties with OCT, the surgeon may determine beforehand which lymph nodes are actually metastatic [138,236,237] and can thus reduce the number of unnecessary resections.

\subsection{Developmental biology}

OCT was introduced to developmental biology in 1996 by Boppart et al. [238]. Nowadays, there is a large number of exciting applications, which we cannot cover in this place. However, we will exemplarily present the promising and fascinating OCT studies on heart development. The heart is the first organ to form and function in vertebrates and undergoes simultaneous structural and functional maturation as it transforms in a dynamic process from a straight tube to a four-chambered heart [239]. Malformations of the heart are among the most common birth defects, and are the leading cause of birth defect-related deaths [240]. However, the cause of most heart defects still remains unknown.

OCT has proven a well-suited tool for studies in different small-animal models that provide fundamental understanding of normal and abnormal heart development in vertebrates. Various groups demonstrated anatomical and functional imaging of the developing cardiovascular system for different species, such as frog tadpoles [242,243], avian embryos (Fig. 12) [241,244], and mouse embryos [245].

Recent studies in this field address so far poorly understood processes during the establishment of a functioning cardiovascular system. OCT recordings on chick embryos in vivo provided new insights about the developing coronary artery system [246] and the contraction dynamics of the early embryonic heart loops [247].

Progress in OCT technology, for instance functional imaging [248,249], high-speed data acquisition [244] or 


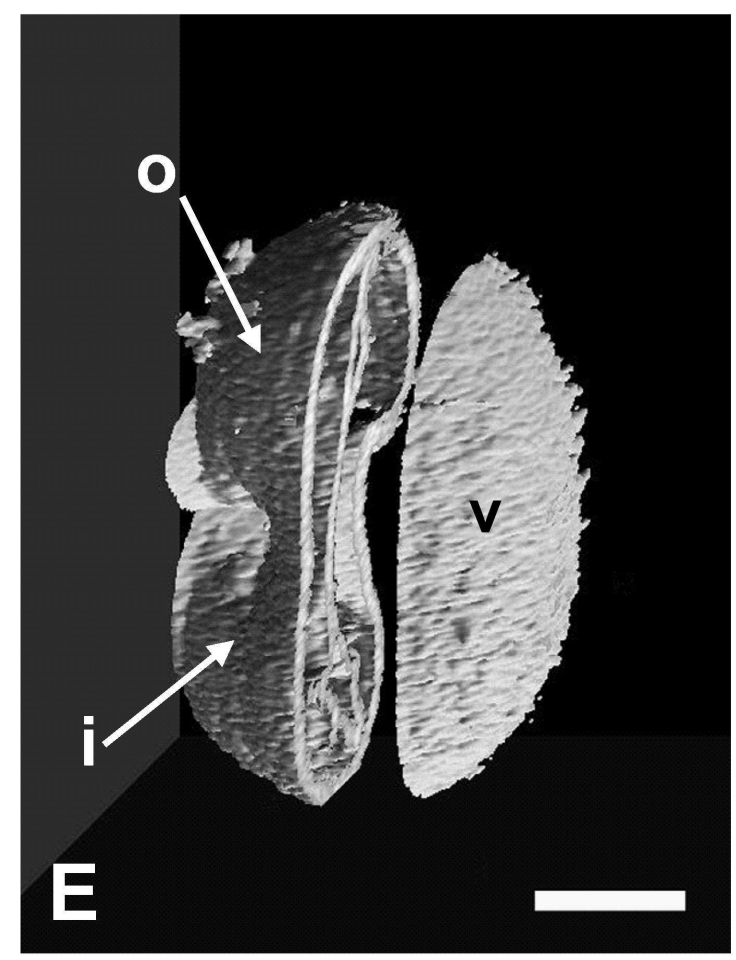

Fig. 123 D OCT scan of a 56 hours old chick embryo heart. The cutaway view reveals further internal structural details. o: outflow limb, i: inflow limb, v: presumptive ventricle. Scale bar: $250 \mu \mathrm{m}$. Printed with permission [241].

advanced signal processing [250], has swiftly been adopted in developmental biology. These enabled further studies in early heart development and blood flow in various models establishing OCT as an important imaging tool for basic research.

\subsection{Combination of modalities}

In many occasions, it appears beneficial to combine OCT with other imaging modalities in order to exploit the advantages of different techniques. The possibilities are numerous, therefore we will focus on some of the most prominent examples.

Multi-Photon Tomography (MPT) is based on nonlinear processes, like two-photon absorption in endogenous fluorophores and second harmonic generation. Providing submicrometer transverse resolution and chemical specificity, MPT has shown promising results in skin cancer diagnosis [251]. It is, however, a comparably slow technique and thus limited to a small field of view, and the penetration depth is limited to a few hundred micrometers. A combined system could perform a fast OCT scan to find a region of interest, which would subsequently be examined in detail with MPT. In a recent study, König et al. demonstrated with correlated OCT and MPT images of skin cancer lesions diagnostic potential of combining these modalities [252]. Already in 2006, Vinegoni et al. presented a combined MPT/OCM system that provides overlaid morphologic and spectroscopic images of different samples [253].

In a similar manner, Raman spectroscopy can add chemical specificity to the structural imaging capability of OCT. It provides a chemical fingerprint of a sample, that can be used to distinguish diseased tissue from healthy $[254,255]$, and is especially promising for diagnosis of early stage cancer or pre-cancer conditions [256,257]. Patil et al. showed that data from Raman spectroscopy can help to accurately classify skin lesions when OCT images alone are ambiguous [258,259].

An important imaging modality in ophthalmology is Scanning Laser Ophthalmoscopy (SLO) which generates en face projections of the eye fundus [260]. SLO and OCT complement each other very well, as Hammer et al. demonstrated in an integrated setup. SLO can provide high-contrast images of fine blood vessels or the photoreceptor mosaic, while OCT resolves the retinal layer structure with high penetration depth [172]. Already commercially available is OCT combined with a scanning laser ophthalmoscope that supports various modes of reflectance and fluorescence imaging [261, 262].

Photo-acoustic Tomography detects sound waves generated by the absorption of short light pulses in tissue [263]. It can with high specificity map the spatial distribution of absorbing substances in the sample, for instance hemoglobin or pigments, and has a penetration depth up to several centimeters. Combined data, for instance general morphological information from OCT and a detailed map of blood vessels, could prove valuable for diagnosing pathologies that affect vasculature, such as diabetic retinopathy or tumors. First devices have successfully acquired combined images of skin morphology and microvasculature [264,265].

\section{Summary}

OCT is a non-invasive optical imaging technique providing real-time two- or three-dimensional images with micrometer resolution and millimeter penetration depth. In a basic configuration, OCT can reveal the morphology of a sample, but functional extensions are possible, as well, which detect the influence on polarization, Doppler shift due to flow of liquid, mechanical or optical properties, or the presence of certain substances in a sample. Technical development aims for faster systems, higher resolution and better image quality. OCT has found manifold applications biomedical research and is 
used on regular basis in the clinic to asses various types of pathologies.

OCT is established as a clinical standard in ophthalmology and has proven invaluable in diagnostics and treatment control of many eye diseases. New commercial systems feature frequency domain data acquisition enabling a significant increase in imaging speed. Functional, especially polarization sensitive imaging is expected to be integrated as a complementary tool for improved accuracy in clinical diagnostics.

The next emerging field of clinical application lies within cardiology, where the first commercial systems have entered the market. Here as well, OCT can provide important information that is hardly accessible with other techniques. For instance, it is applied for guidance and follow-up of coronary interventions, such as stent deployment, and may be used to assess the risk of myocardial infarction. Intravascular OCT is therefore expected to become a clinical standard in cardiology within the next decade.

The value of OCT imaging in dermatology has been investigated for many years. Numerous studies show the potential of OCT for skin cancer diagnosis, but current technology does not yet provide sufficient accuracy for clinical use. Significant improvements of resolution, penetration depth or image quality are required to make OCT feasible for clinical dermatologic applications. However, functional imaging, for instance polarization sensitive OCT, or the combination with other modalities such as Multiphoton Tomography may open new possibilities to improve diagnostic accuracy.

Currently available clinical OCT systems provide only structural images. However, technology to acquire functional information has matured so far that some of these techniques, e. g. PS-OCT, are expected to be part of the next generation of OCT systems. The combination of OCT with other modalities is progressing in a similar manner. Whereas some combinations of modalities, e.g. OCT and Scanning Laser Ophthalmoscopy, are already on the market, others are currently under development, e.g. OCT and Multiphoton Tomography, and may become available within the next years. Hence, a variety of new instruments for clinical diagnostics and biomedical research will become available in the near future.

Acknowledgements We would like to thank Rainer Leitgeb and Lars Thrane for their contributions. We feel indebted to the editors for giving us the opportunity to contribute to this issue of Analytical and Bioanalytical Chemistry, and to the referees for their helpful comments and suggestions. Further, we gratefully acknowledge the financial support by the European Union project FUN OCT (FP7 HEALTH, contract no. 201880).

\section{References}

1. D. Huang, E. A. Swanson, C. P. Lin, J. S. Schuman, W. G. Stinson, W. Chang, M. R. Hee, T. Flotte, K. Gregory, C. A. Puliafito, and J. G. Fujimoto, "Optical coherence tomography," Science, vol. 254, no. 5035, pp. $1178-1181,1991$.

2. G. Smolka, "Optical coherence tomography - 2010: Technology, applications, and markets," market report OM-51, Strategies Unlimited, 2010.

3. "LightLab Imaging announces FDA clearance of C7$\mathrm{XR}^{\mathrm{TM}}$ coronary OCT products in the United States." www.octnews.org, May 5 2010. Accessed 13 Nov 2010.

4. "Volcano Corporation announces receipt of $\mathrm{CE}$ mark for its OCT imaging system and catheter." ir.volcanocorp.com/releases.cfm, Jan 5 2010. Accessed 17 Mar 2011.

5. I. Hartl, X. D. Li, C. Chudoba, R. K. Ghanta, T. H. Ko, J. G. Fujimoto, J. K. Ranka, and R. S. Windeler, "Ultrahigh-resolution optical coherence tomography using continuum generation in an air-silica microstructure optical fiber," Opt. Lett., vol. 26, no. 9, pp. 608-610, 2001.

6. B. Považay, K. Bizheva, A. Unterhuber, B. Hermann, H. Sattmann, A. F. Fercher, W. Drexler, A. Apolonski, W. J. Wadsworth, J. C. Knight, P. S. J. Russell, M. Vetterlein, and E. Scherzer, "Submicrometer axial resolution optical coherence tomography," Opt. Lett., vol. 27, no. 20, pp. 1800-1802, 2002.

7. W. Drexler, "Ultrahigh-resolution optical coherence tomography," J. Biomed. Opt., vol. 9, no. 1, pp. 47-74, 2004.

8. S. Inoué, Handbook of Biological Confocal Microscopy, ch. 1. Springer Science+Business Media, LLC, 3 ed., 2006. ISBN: 978-0-387-25921-5.

9. D. Stifter, "Beyond biomedicine: a review of alternative applications and developments for optical coherence tomography," Appl. Phys. B-Lasers O., vol. 88, no. 3, pp. 337-357, 2007.

10. A. F. Fercher, "Optical coherence tomography - development, principles, applications," Z. Med. Phys., vol. 20 , no. 4, pp. 251-276, 2010.

11. M. E. Brezinski, Optical Coherence Tomography - Principles and Applications. Academic Press, 2006.

12. W. Drexler and J. G. Fujimoto, eds., Optical Coherence Tomography - Technology and Applications. Springer, 2008.

13. K. Takada, I. Yokohama, K. Chida, and J. Noda, "New measurement system for fault location in optical waveguide devices based on an interferometric technique," Appl. Opt., vol. 26, pp. 1603-1606, May 1987.

14. A. F. Fercher, K. Mengedoht, and W. Werner, "Eyelength measurement by interferometry with partially coherent light," Opt. Lett., vol. 13, pp. 186-188, Mar 1988.

15. A. F. Fercher, C. K. Hitzenberger, G. Kamp, and S. Y. El-Zaiat, "Measurement of intraocular distances by backscattering spectral interferometry," Opt. Commun., vol. 117, no. 1-2, pp. 43-48, 1995.

16. M. A. Bail, G. Häusler, J. M. Herrmann, M. W. Lindner, and R. Ringler, "Optical coherence tomography with the "spectral radar": fast optical analysis in volume scatterers by short-coherence interferometry," Proc. SPIE, vol. 2925, pp. 298-303, 1996.

17. G. Häusler and M. W. Lindner, "'coherence radar' and 'spectral radar' - new tools for dermatological diagnosis," J. Biomed. Opt., vol. 3, no. 1, pp. 21-31, 1998. 
18. U. Haberland, W. Rütten, V. Blazek, and H. J. Schmitt, "Investigation of highly scattering media using nearinfrared continuous wave tunable semiconductor laser," Proc. SPIE, vol. 2389, pp. 503-512, 1995.

19. S. R. Chinn, E. A. Swanson, and J. G. Fujimoto, "Optical coherence tomography using a frequency-tunable optical source," Opt. Lett., vol. 22, no. 5, pp. 340-342, 1997.

20. B. Golubovic, B. E. Bouma, G. J. Tearney, and J. G. Fujimoto, "Optical frequency-domain reflectometry using rapid wavelength tuning of a $\mathrm{Cr}^{4+}$ :forsterite laser," Opt. Lett., vol. 22, no. 22, pp. 1704-1706, 1997.

21. W. Eickhoff and R. Ulrich, "Optical frequency domain reflectometry in single-mode fiber," Appl. Phys. Lett., vol. 39, pp. 693-695, 1981.

22. D. Uttam and B. Culshaw, "Precision time domain reflectometry in optical fiber systems using a frequency modulated continuous wave ranging technique," J. Lightwave Technol., vol. 3, no. 5, pp. 971-977, 1985.

23. S.-H. Yun, C. Boudoux, G. J. Tearney, and B. E. Bouma, "High-speed wavelength-swept semiconductor laser with a polygon-scanner-based wavelength filter," Opt. Lett., vol. 28, no. 20, pp. 1981-1983, 2003.

24. M. A. Choma, K. Hsu, and J. A. Izatt, "Swept source optical coherence tomography using an all-fiber 1300nm ring laser source," J. Biomed. Opt., vol. 10, no. 4, p. 044009, 2005.

25. R. Huber, M. Wojtkowski, K. Taira, J. G. Fujimoto, and K. Hsu, "Amplified, frequency swept lasers for frequency domain reflectometry and OCT imaging: Design and scaling principles," Opt. Express, vol. 13, no. 9, pp. 3513-3528, 2005.

26. R. Huber, M. Wojtkowski, and J. G. Fujimoto, "Fourier domain mode locking (FDML): a new laser operating regime and applications for optical coherence tomography," Opt. Express, vol. 14, no. 8, pp. 3225-3237, 2006.

27. W. Wieser, B. R. Biedermann, T. Klein, C. M. Eigenwillig, and R. Huber, "Multi-megahertz OCT: High quality $3 \mathrm{D}$ imaging at 20 million A-scans and 4.5 Gvoxels per second," Opt. Express, vol. 18, no. 14, pp. 14685-14704, 2010.

28. B. Liu and M. E. Brezinski, "Theoretical and practical considerations on detection performance of time domain, fourier domain, and swept source optical coherence tomography," J. Biomed. Opt., vol. 12, no. 4, p. $044007,2007$.

29. R. A. Leitgeb, C. K. Hitzenberger, A. F. Fercher, and T. Bajraszewski, "Phase-shifting algorithm to achieve high-speed long-depth-range probing by frequencydomain optical coherence tomography," Opt. Lett., vol. 28, pp. 2201-2203, Nov 2003.

30. M. Sarunic, M. A. Choma, C. Yang, and J. A. Izatt, "Instantaneous complex conjugate resolved spectral domain and swept-source oct using $3 \times 3$ fiber couplers," Opt. Express, vol. 13, pp. 957-967, Feb 2005.

31. J. Zhang, J. S. Nelson, and Z. Chen, "Removal of a mirror image and enhancement of the signal-to-noise ratio in fourier-domain optical coherence tomography using an electro-optic phase modulator," Opt. Lett., vol. 30, pp. 147-149, Jan 2005.

32. Y. Yasuno, S. Makita, T. Endo, G. Aoki, M. Itoh, and T. Yatagai, "Simultaneous B-M-mode scanning method for real-time full-range fourier domain optical coherence tomography," Appl. Opt., vol. 45, pp. 1861-1865, Mar 2006 .
33. L. An and R. K. Wang, "Use of a scanner to modulate spatial interferograms for in vivo full-range fourierdomain optical coherence tomography," Opt. Lett., vol. 32, pp. 3423-3425, Dec 2007.

34. S. M. R. M. Nezam, B. J. Vakoc, A. E. Desjardins, G. J. Tearney, and B. E. Bouma, "Increased ranging depth in optical frequency domain imaging by frequency encoding," Opt. Lett., vol. 32, no. 19, pp. 2768-2770, 2007.

35. B. Hofer, B. Považay, B. Hermann, A. Unterhuber, G. Matz, and W. Drexler, "Dispersion encoded full range frequency domain optical coherence tomography," Opt. Express, vol. 17, pp. 7-24, Jan 2009.

36. B. E. Bouma, S.-H. Yun, B. J. Vakoc, M. J. Suter, and G. J. Tearney, "Fourier-domain optical coherence tomography: recent advances toward clinical utility," Curr. Opin. Biotech., vol. 20, no. 1, pp. 111-118, 2009.

37. R. Huber, D. C. Adler, V. J. Srinivasan, and J. G. Fujimoto, "Fourier domain mode locking at $1050 \mathrm{~nm}$ for ultra-high-speed optical coherence tomography of the human retina at 236,000 axial scans per second," Opt. Lett., vol. 32, no. 14, pp. 2049-2051, 2007.

38. S. Marschall, T. Klein, W. Wieser, B. R. Biedermann, K. Hsu, K. P. Hansen, B. Sumpf, K.-H. Hasler, G. Erbert, O. B. Jensen, C. Pedersen, R. Huber, and P. E. Andersen, "Fourier domain mode-locked swept source at $1050 \mathrm{~nm}$ based on a tapered amplifier," Opt. Express, vol. 18, no. 15, pp. 15820-15831, 2010.

39. J. Holmes, S. Hattersley, N. Stone, F. Bazant-Hegemark, and H. Barr, "Multi-channel fourier domain OCT system with superior lateral resolution for biomedical applications," Proc. SPIE, vol. 6847, p. 68470O, 2008.

40. J. A. Izatt, M. R. Hee, G. M. Owen, E. A. Swanson, and J. G. Fujimoto, "Optical coherence microscopy in scattering media," Opt. Lett., vol. 19, pp. 590-592, Apr 1994.

41. G. J. Tearney, M. E. Brezinski, B. E. Bouma, S. A. Boppart, C. Pitris, J. F. Southern, and J. G. Fujimoto, "In vivo endoscopic optical biopsy with optical coherence tomography," Science, vol. 276, no. 5321, pp. 2037-2039, 1997.

42. X. Li, C. Chudoba, T. Ko, C. Pitris, and J. G. Fujimoto, "Imaging needle for optical coherence tomography," Opt. Lett., vol. 25, pp. 1520-1522, Oct 2000.

43. S.-H. Yun, G. J. Tearney, J. F. de Boer, and B. E. Bouma, "Motion artifacts in optical coherence tomography with frequency-domain ranging," Opt. Express, vol. 12, no. 13, pp. 2977-2998, 2004.

44. K. Bizheva, R. Pflug, B. Hermann, B. Považay, H. Sattmann, P. Qiu, E. Angers, H. Reitsamer, S. Popov, J. R. Taylor, A. Unterhuber, P. Ahnelt, and W. Drexler, "Optophysiology: Depth-resolved probing of retinal physiology with functional ultrahighresolution optical coherence tomography," $P$. Natl. Acad. Sci. USA, vol. 103, no. 13, 2006.

45. R. A. Leitgeb, T. Schmoll, and C. Kolbitsch, "Dynamic retinal optical coherence microscopy without adaptive optics," Proc. SPIE, vol. 7372, p. 737208, 2009.

46. J. M. Schmitt, A. Knüttel, M. Yadlowsky, and M. A. Eckhaus, "Optical-coherence tomography of a dense tissue: statistics of attenuation and backscattering," Phys. Med. Biol., vol. 39, no. 10, pp. 1705-1720, 1994.

47. C. K. Hitzenberger, A. Baumgartner, W. Drexler, and A. F. Fercher, "Dispersion effects in partial coherence interferometry: Implications for intraocular ranging," $J$. Biomed. Opt., vol. 4, no. 1, pp. 144-151, 1999. 
48. J. F. de Boer, C. E. Saxer, and J. S. Nelson, "Stable carrier generation and phase-resolved digital data processing in optical coherence tomography," Appl. Opt., vol. 40, pp. 5787-5790, Nov 2001.

49. M. E. Brezinski, G. J. Tearney, B. E. Bouma, J. A. Izatt, M. R. Hee, E. A. Swanson, J. F. Southern, and J. G. Fujimoto, "Optical coherence tomography for optical biopsy: Properties and demonstration of vascular pathology," Circulation, vol. 93, no. 6, pp. 1206-1213, 1996.

50. J. A. Parrish, "New concepts in therapeutic photomedicine; photochemistry, optical targeting and the therapeutic window," J. Invest. Dermatol., vol. 77, pp. 45-50, July 1981.

51. U. Sharma, E. W. Chang, and S. H. Yun, "Longwavelength optical coherence tomography at $1.7 \mu \mathrm{m}$ for enhanced imaging depth," Opt. Express, vol. 16, pp. 19712-19723, Nov 2008.

52. B. Považay, K. Bizheva, B. Hermann, A. Unterhuber, H. Sattmann, A. F. Fercher, W. Drexler, C. Schubert, P. K. Ahnelt, M. Mei, R. Holzwarth, W. J. Wadsworth, J. C. Knight, and P. S. J. Russel, "Enhanced visualization of choroidal vessels using ultrahigh resolution ophthalmic OCT at $1050 \mathrm{~nm}$," Opt. Express, vol. 11, no. 17, pp. 1980-1986, 2003.

53. Y. Wang, J. S. Nelson, Z. Chen, B. J. Reiser, R. S. Chuck, and R. S. Windeler, "Optimal wavelength for ultrahigh-resolution optical coherence tomography," Opt. Express, vol. 11, no. 12, pp. 1411-1417, 2003.

54. J. M. Schmitt, S. H. Xiang, and K. M. Yung, "Speckle in optical coherence tomography," J. Biomed. Opt., vol. 4, no. 1, pp. 95-105, 1999.

55. K. W. Gossage, T. S. Tkaczyk, J. J. Rodriguez, and J. K. Barton, "Texture analysis of optical coherence tomography images: feasibility for tissue classification," $J$. Biomed. Opt., vol. 8, no. 3, pp. 570-575, 2003.

56. T. R. Hillman, S. G. Adie, V. Seemann, J. J. Armstrong, S. L. Jacques, and D. D. Sampson, "Correlation of static speckle with sample properties in optical coherence tomography," Opt. Lett., vol. 31, pp. 190-192, Jan 2006.

57. J. M. Schmitt, "Array detection for speckle reduction in optical coherence microscopy," Phys. Med. Biol., vol. 42, no. 7, pp. 1427-1439, 1997.

58. B. Sander, M. Larsen, L. Thrane, J. L. Hougaard, and T. M. Jørgensen, "Enhanced optical coherence tomography imaging by multiple scan averaging," Brit. J. Ophthalmol., vol. 89, no. 2, pp. 207-212, 2005.

59. T. M. Jørgensen, J. Thomadsen, U. Christensen, W. Soliman, and B. Sander, "Enhancing the signal-tonoise ratio in ophthalmic optical coherence tomography by image registration - method and clinical examples," J. Biomed. Opt., vol. 12, no. 4, p. 041208, 2007.

60. M. Pircher, E. Götzinger, R. Leitgeb, A. F. Fercher, and C. K. Hitzenberger, "Speckle reduction in optical coherence tomography by frequency compounding," $J$. Biomed. Opt., vol. 8, no. 3, pp. 565-569, 2003.

61. M. D. Kulkarni, C. W. Thomas, and J. A. Izatt, "Image enhancement in optical coherence tomography using deconvolution," Electron. Lett., vol. 33, pp. 1365-1367, July 1997.

62. J. M. Schmitt, "Restoration of optical coherence images of living tissue using the CLEAN algorithm," $J$. Biomed. Opt., vol. 3, no. 1, pp. 66-75, 1998.

63. S. H. Xiang, L. Zhou, and J. M. Schmitt, "Speckle noise reduction for optical coherence tomography," Proc. SPIE, vol. 3196, no. 1, pp. 79-88, 1998.
64. J. Rogowska and M. E. Brezinski, "Evaluation of the adaptive speckle suppression filter for coronary optical coherence tomography imaging," IEEE T. Med. Imaging, vol. 19, no. 12, pp. 1261-1266, 2000.

65. R. K. Wang, "Reduction of speckle noise for optical coherence tomography by the use of nonlinear anisotropic diffusion," Proc. SPIE, vol. 5690, no. 1, pp. 380-385, 2005.

66. A. F. Fercher, W. Drexler, C. K. Hitzenberger, and T. Lasser, "Optical coherence tomography - principles and applications," Rep. Prog. Phys., vol. 66, pp. 239303, 2003.

67. M. R. Hee, D. Huang, E. A. Swanson, and J. G. Fujimoto, "Polarization-sensitive low-coherence reflectometer for birefringence characterization and ranging," $J$. Opt. Soc. Am. B, vol. 9, no. 6, pp. 903-908, 1992.

68. J. F. de Boer, T. E. Milner, M. J. C. van Gemert, and J. S. Nelson, "Two-dimensional birefringence imaging in biological tissue by polarization-sensitive optical coherence tomography," Opt. Lett., vol. 22, pp. 934-936, Jun 1997.

69. A. Baumgartner, S. Dichtl, C. K. Hitzenberger, H. Sattmann, B. Robl, A. Moritz, A. F. Fercher, and W. Sperr, "Polarization-sensitive optical coherence tomography of dental structures," Caries Res., vol. 34, no. 1 , pp. 59-69, 2000.

70. N. Kemp, H. Zaatari, J. Park, H. G. R. III, and T. Milner, "Form-biattenuance in fibrous tissues measured with polarization-sensitive optical coherence tomography (PS-OCT)," Opt. Express, vol. 13, pp. 4611-4628, Jun 2005.

71. M. Pircher, E. Götzinger, R. Leitgeb, H. Sattmann, O. Findl, and C. Hitzenberger, "Imaging of polarization properties of human retina in vivo with phase resolved transversal PS-OCT," Opt. Express, vol. 12, pp. 59405951, Nov 2004.

72. J. F. de Boer, T. E. Milner, and J. S. Nelson, "Determination of the depth-resolved Stokes parameters of light backscattered from turbid media by use of polarizationsensitive optical coherence tomography," Opt. Lett., vol. 24, pp. 300-302, Mar 1999.

73. G. Yao and L. V. Wang, "Two-dimensional depthresolved Mueller matrix characterization of biological tissue by optical coherence tomography," Opt. Lett., vol. 24, pp. 537-539, Apr 1999.

74. S. Jiao and L. V. Wang, "Jones-matrix imaging of biological tissues with quadruple-channel optical coherence tomography," J. Biomed. Opt., vol. 7, no. 3, pp. 350$358,2002$.

75. C. K. Hitzenberger, E. Götzinger, M. Sticker, M. Pircher, and A. F. Fercher, "Measurement and imaging of birefringence and optic axis orientation by phase resolved polarization sensitive optical coherence tomography," Opt. Express, vol. 9, no. 13, pp. 780-790, 2001.

76. E. Götzinger, B. Baumann, M. Pircher, and C. K. Hitzenberger, "Polarization maintaining fiber based ultra-high resolution spectral domain polarization sensitive optical coherence tomography," Opt. Express, vol. 17, pp. 22704-22717, Dec 2009.

77. Y. Yasuno, S. Makita, Y. Sutoh, M. Itoh, and T. Yatagai, "Birefringence imaging of human skin by polarization-sensitive spectral interferometric optical coherence tomography," Opt. Lett., vol. 27, pp. 18031805, Oct 2002.

78. W. Y. Oh, S. H. Yun, B. J. Vakoc, M. Shishkov, A. E. Desjardins, B. H. Park, J. F. de Boer, G. J. Tearney, and B. E. Bouma, "High-speed polarization sensitive 
optical frequency domain imaging with frequency multiplexing," Opt. Express, vol. 16, pp. 1096-1103, Jan 2008.

79. M. Yamanari, S. Makita, and Y. Yasuno, "Polarizationsensitive swept-source optical coherence tomography with continuous source polarization modulation," Opt. Express, vol. 16, pp. 5892-5906, Apr 2008.

80. C. E. Saxer, J. F. de Boer, B. H. Park, Y. Zhao, Z. Chen, and J. S. Nelson, "High-speed fiber based polarizationsensitive optical coherence tomography of in vivo human skin," Opt. Lett., vol. 25, pp. 1355-1357, Sep 2000.

81. J. E. Roth, J. A. Kozak, S. Yazdanfar, A. M. Rollins, and J. A. Izatt, "Simplified method for polarizationsensitive optical coherence tomography," Opt. Lett., vol. 26, pp. 1069-1071, Jul 2001.

82. D. P. Davé, T. Akkin, and T. E. Milner, "Polarizationmaintaining fiber-based optical low-coherence reflectometer for characterization and ranging of birefringence," Opt. Lett., vol. 28, pp. 1775-1777, Oct 2003.

83. B. Liu, M. Harman, S. Giattina, D. L. Stamper, C. Demakis, M. Chilek, S. Raby, and M. E. Brezinski, "Characterizing of tissue microstructure with single-detector polarization-sensitive optical coherence tomography," Appl. Opt., vol. 45, pp. 4464-4479, Jun 2006.

84. S. D. Giattina, B. K. Courtney, P. R. Herz, M. Harman, S. Shortkroff, D. L. Stamper, B. Liu, J. G. Fujimoto, and M. E. Brezinski, "Assessment of coronary plaque collagen with polarization sensitive optical coherence tomography (PS-OCT)," Int. J. Cardiol., vol. 107, no. 3, pp. 400-409, 2006.

85. K. Zheng, C. Rashidifard, B. Liu, and M. Brezinski, "Comparison of artifact generation with catheter bending using different PS-OCT approaches," Reports in Medical Imaging, vol. 2, pp. 49-54, 2009.

86. J. A. Izatt, M. D. Kulkarni, S. Yazdanfar, J. K. Barton, and A. J. Welch, "In vivo bidirectional color Doppler flow imaging of picoliter blood volumes using optical coherence tomography," Opt. Lett., vol. 22, pp. 14391441, Sep 1997.

87. Z. Chen, T. E. Milner, D. Davé, and J. S. Nelson, "Optical Doppler tomographic imaging of fluid flow velocity in highly scattering media," Opt. Lett., vol. 22, pp. 6466, Jan 1997.

88. Y. Zhao, Z. Chen, C. Saxer, S. Xiang, J. F. de Boer, and J. S. Nelson, "Phase-resolved optical coherence tomography and optical Doppler tomography for imaging blood flow in human skin with fast scanning speed and high velocity sensitivity," Opt. Lett., vol. 25, pp. 114116, Jan 2000.

89. R. Leitgeb, L. Schmetterer, M. Wojtkowski, C. K. Hitzenberger, M. Sticker, and A. F. Fercher, "Flow velocity measurements by frequency domain short coherence interferometry," Proc. SPIE, vol. 4619, pp. 16-21, 2002.

90. B. Vakoc, S. Yun, J. de Boer, G. Tearney, and B. Bouma, "Phase-resolved optical frequency domain imaging," Opt. Express, vol. 13, no. 14, pp. 5483-5493, 2005.

91. D. C. Adler, R. Huber, and J. G. Fujimoto, "Phasesensitive optical coherence tomography at up to 370,000 lines per second using buffered Fourier domain modelocked lasers," Opt. Lett., vol. 32, no. 6, pp. 626-628, 2007.

92. C. Yang, A. Wax, M. S. Hahn, K. Badizadegan, R. R. Dasari, and M. S. Feld, "Phase-referenced interferometer with subwavelength and subhertz sensitivity applied to the study of cell membrane dynamics," Opt. Lett., vol. 26, pp. 1271-1273, Aug 2001.
93. M. Sticker, M. Pircher, E. Götzinger, H. Sattmann, A. F. Fercher, and C. K. Hitzenberger, "En face imaging of single cell layers by differential phase-contrast optical coherence microscopy," Opt. Lett., vol. 27, pp. 11261128, Jul 2002.

94. M. A. Choma, A. K. Ellerbee, C. Yang, T. L. Creazzo, and J. A. Izatt, "Spectral-domain phase microscopy," Opt. Lett., vol. 30, pp. 1162-1164, May 2005.

95. C. K. Hitzenberger and A. F. Fercher, "Differential phase contrast in optical coherence tomography," Opt. Lett., vol. 24, pp. 622-624, May 1999.

96. D. P. Davé and T. E. Milner, "Optical low-coherence reflectometer for differential phase measurement," Opt. Lett., vol. 25, pp. 227-229, Feb 2000.

97. S. A. Telenkov, D. P. Davé, S. Sethuraman, T. Akkin, and T. E. Milner, "Differential phase optical coherence probe for depth-resolved detection of photothermal response in tissue," Phys. Med. Biol., vol. 49, no. 1, pp. 111-119, 2004.

98. H. Iwai, C. Fang-Yen, G. Popescu, A. Wax, K. Badizadegan, R. R. Dasari, and M. S. Feld, "Quantitative phase imaging using actively stabilized phase-shifting lowcoherence interferometry," Opt. Lett., vol. 29, pp. 23992401 , Oct 2004.

99. C. Joo, T. Akkin, B. Cense, B. H. Park, and J. F. de Boer, "Spectral-domain optical coherence phase microscopy for quantitative phase-contrast imaging," Opt. Lett., vol. 30, pp. 2131-2133, Aug 2005.

100. J. M. Schmitt, "OCT elastography: imaging microscopic deformation and strain of tissue," Opt. Express, vol. 3, pp. 199-211, Sep 1998.

101. R. Chan, A. Chau, W. Karl, S. Nadkarni, A. Khalil, N. Iftimia, M. Shishkov, G. Tearney, M. KaazempurMofrad, and B. Bouma, "OCT-based arterial elastography: robust estimation exploiting tissue biomechanics," Opt. Express, vol. 12, pp. 4558-4572, Sep 2004.

102. J. Rogowska, N. Patel, S. Plummer, and M. E. Brezinski, "Quantitative optical coherence tomographic elastography: method for assessing arterial mechanical properties," Brit. J. Radiol., vol. 79, no. 945, pp. 707-711, 2006.

103. G. van Soest, F. Mastik, N. de Jong, and A. F. W. van der Steen, "Robust intravascular optical coherence elastography by line correlations," Phys. Med. Biol., vol. 52, no. 9, pp. 2445-2458, 2007.

104. R. K. Wang, Z. Ma, and S. J. Kirkpatrick, "Tissue Doppler optical coherence elastography for real time strain rate and strain mapping of soft tissue," Appl. Phys. Lett., vol. 89, no. 14, p. 144103, 2006.

105. S. J. Kirkpatrick, R. K. Wang, and D. D. Duncan, "OCT-based elastography for large and small deformations," Opt. Express, vol. 14, pp. 11585-11597, Nov 2006.

106. X. Liang, A. L. Oldenburg, V. Crecea, E. J. Chaney, and S. A. Boppart, "Optical micro-scale mapping of dynamic biomechanical tissue properties," Opt. Express, vol. 16, pp. 11052-11065, Jul 2008.

107. S. G. Adie, B. F. Kennedy, J. J. Armstrong, S. A. Alexandrov, and D. D. Sampson, "Audio frequency in vivo optical coherence elastography," Phys. Med. Biol., vol. 54, no. 10, pp. 3129-3139, 2009.

108. S. G. Adie, X. Liang, B. F. Kennedy, R. John, D. D. Sampson, and S. A. Boppart, "Spectroscopic optical coherence elastography," Opt. Express, vol. 18, pp. 2551925534, Dec 2010.

109. B. F. Kennedy, T. R. Hillman, R. A. McLaughlin, B. C. Quirk, and D. D. Sampson, "In vivo dynamic optical 
coherence elastography using a ring actuator," Opt. Express, vol. 17 , pp. $21762-21772$, Nov 2009.

110. X. Liang and S. A. Boppart, "Biomechanical properties of in vivo human skin from dynamic optical coherence elastography," IEEE T. Biomed. Eng., vol. 57, pp. 953959, april 2010.

111. C. Yang, "Molecular contrast optical coherence tomography: A review," Photochem. Photobiol., vol. 81, no. 2, pp. 215-237, 2005.

112. S. A. Boppart, A. L. Oldenburg, C. Xu, and D. L. Marks, "Optical probes and techniques for molecular contrast enhancement in coherence imaging," J. Biomed. Opt., vol. 10, no. 4, p. 041208, 2005.

113. U. Morgner, W. Drexler, F. X. Kärtner, X. D. Li, C. Pitris, E. P. Ippen, and J. G. Fujimoto, "Spectroscopic optical coherence tomography," Opt. Lett., vol. 25, pp. 111-113, Jan 2000.

114. D. J. Faber, E. G. Mik, M. C. G. Aalders, and T. G. van Leeuwen, "Light absorption of (oxy-)hemoglobin assessed by spectroscopic optical coherence tomography," Opt. Lett., vol. 28, pp. 1436-1438, Aug 2003.

115. C. Yang, L. E. L. McGuckin, J. D. Simon, M. A. Choma, B. E. Applegate, and J. A. Izatt, "Spectral triangulation molecular contrast optical coherence tomography with indocyanine green as the contrast agent," Opt. Lett., vol. 29, pp. 2016-2018, Sep 2004.

116. C. Xu, D. Marks, M. Do, and S. Boppart, "Separation of absorption and scattering profiles in spectroscopic optical coherence tomography using a least-squares algorithm," Opt. Express, vol. 12, pp. 4790-4803, Oct 2004.

117. J. M. Schmitt, S. H. Xiang, and K. M. Yung, "Differential absorption imaging with optical coherence tomography," J. Opt. Soc. Am. A, vol. 15, pp. 2288-2296, Sep 1998

118. C.-W. Lu, C.-K. Lee, M.-T. Tsai, Y.-M. Wang, and C. C. Yang, "Measurement of the hemoglobin oxygen saturation level with spectroscopic spectral-domain optical coherence tomography," Opt. Lett., vol. 33, pp. 416418, Mar 2008.

119. C. Vinegoni, J. Bredfeldt, D. Marks, and S. Boppart, "Nonlinear optical contrast enhancement for optical coherence tomography," Opt. Express, vol. 12, pp. 331341, Jan 2004.

120. Y. Jiang, I. Tomov, Y. Wang, and Z. Chen, "Secondharmonic optical coherence tomography," Opt. Lett., vol. 29, pp. 1090-1092, May 2004.

121. B. E. Applegate, C. Yang, A. M. Rollins, and J. A. Izatt, "Polarization-resolved second-harmonic-generation optical coherence tomography in collagen," Opt. Lett., vol. 29 , pp. 2252-2254, Oct 2004.

122. J. S. Bredfeldt, C. Vinegoni, D. L. Marks, and S. A. Boppart, "Molecularly sensitive optical coherence tomography," Opt. Lett., vol. 30, pp. 495-497, Mar 2005.

123. T. Støren, A. Simonsen, O. J. Løkberg, T. Lindmo, L. O. Svaasand, and A. Røyset, "Measurement of dye diffusion in agar gel by use of low-coherence interferometry," Opt. Lett., vol. 28, pp. 1215-1217, Jul 2003.

124. K. D. Rao, M. A. Choma, S. Yazdanfar, A. M. Rollins, and J. A. Izatt, "Molecular contrast in optical coherence tomography by use of a pump probe technique," Opt. Lett., vol. 28, pp. 340-342, Mar 2003.

125. J. K. Barton, J. B. Hoying, and C. J. Sullivan, "Use of microbubbles as an optical coherence tomography contrast agent," Acad. Radiol., vol. 9, no. suppl 1, pp. 52$55,2002$.

126. T. M. Lee, A. L. Oldenburg, S. Sitafalwalla, D. L. Marks, W. Luo, F. J.-J. Toublan, K. S. Suslick, and
S. A. Boppart, "Engineered microsphere contrast agents for optical coherence tomography," Opt. Lett., vol. 28, pp. 1546-1548, Sep 2003.

127. J. K. Barton, N. J. Halas, J. L. West, and R. A. Drezek, "Nanoshells as an optical coherence tomography contrast agent," Proc. SPIE, vol. 5316, pp. 99-106, 2004.

128. T. S. Troutman, J. K. Barton, and M. Romanowski, "Optical coherence tomography with plasmon resonant nanorods of gold," Opt. Lett., vol. 32, pp. 1438-1440, Jun 2007.

129. A. M. Winkler, P. F. S. Rice, R. A. Drezek, and J. K. Barton, "Quantitative tool for rapid disease mapping using optical coherence tomography images of azoxymethane-treated mouse colon," J. Biomed. Opt., vol. 15, no. 4, p. 041512, 2010.

130. G. J. Tearney, M. E. Brezinski, J. F. Southern, B. E. Bouma, M. R. Hee, and J. G. Fujimoto, "Determination of the refractive index of highly scattering human tissue by optical coherence tomography," Opt. Lett., vol. 20, pp. 2258-2260, Nov 1995.

131. A. Knüttel and M. Boehlau-Godau, "Spatially confined and temporally resolved refractive index and scattering evaluation in human skin performed with optical coherence tomography," J. Biomed. Opt., vol. 5, no. 1, pp. 83-92, 2000.

132. L. Thrane, H. T. Yura, and P. E. Andersen, "Analysis of optical coherence tomography systems based on the extended Huygens-Fresnel principle," J. Opt. Soc. Am. $A$, vol. 17, pp. 484-490, Mar 2000.

133. D. Levitz, L. Thrane, M. Frosz, P. Andersen, C. Andersen, S. Andersson-Engels, J. Valanciunaite, J. Swartling, and P. Hansen, "Determination of optical scattering properties of highly-scattering media in optical coherence tomography images," Opt. Express, vol. 12, pp. 249-259, Jan 2004.

134. I. V. Turchin, E. A. Sergeeva, L. S. Dolin, V. A. Kamensky, N. M. Shakhova, and R. Richards-Kortum, "Novel algorithm of processing optical coherence tomography images for differentiation of biological tissue pathologies," J. Biomed. Opt., vol. 10, no. 6, p. 064024, 2005.

135. F. J. van der Meer, D. J. Faber, D. M. B. Sassoon, M. C. Aalders, G. Pasterkamp, and T. G. van Leeuwen, "Localized measurement of optical attenuation coefficients of atherosclerotic plaque constituents by quantitative optical coherence tomography," IEEE T. Med. Imaging, vol. 24, no. 10, pp. 1369-1376, 2005.

136. M. Sowa, D. Popescu, J. Werner, M. Hewko, A. Ko, J. Payette, C. Dong, B. Cleghorn, and L.-P. ChooSmith, "Precision of Raman depolarization and optical attenuation measurements of sound tooth enamel," Anal. Bioanal. Chem., vol. 387, pp. 1613-1619, 2007. 10.1007/s00216-006-0856-9.

137. G. van Soest, T. Goderie, E. Regar, S. Koljenović, G. L. J. H. van Leenders, N. Gonzalo, S. van Noorden, T. Okamura, B. E. Bouma, G. J. Tearney, J. W. Oosterhuis, P. W. Serruys, and A. F. W. van der Steen, "Atherosclerotic tissue characterization in vivo by optical coherence tomography attenuation imaging," J. Biomed. Opt., vol. 15 , no. 1 , p. $011105,2010$.

138. R. A. McLaughlin, L. Scolaro, P. Robbins, C. Saunders, S. L. Jacques, and D. D. Sampson, "Parametric imaging of cancer with optical coherence tomography," $J$. Biomed. Opt., vol. 15, no. 4, p. 046029, 2010.

139. A. F. Fercher, C. K. Hitzenberger, W. Drexler, G. Kamp, and H. Sattmann, "In vivo optical coherence tomography," Am. J. Ophthalmol., vol. 116, no. 1, pp. 113-114, 1993. 
140. E. A. Swanson, J. A. Izatt, M. R. Hee, D. Huang, C. P. Lin, J. S. Schuman, C. A. Puliafito, and J. G. Fujimoto, "In vivo retinal imaging by optical coherence tomography," Opt. Lett., vol. 18, pp. 1864-1866, Nov 1993.

141. J. A. Izatt, M. R. Hee, D. Huang, J. G. Fujimoto, E. A. Swanson, C. P. Lin, J. S. Shuman, and C. A. Puliafito, "Ophthalmic diagnostics using optical coherence tomography," Proc. SPIE, vol. 1877, pp. 136-144, 1993.

142. N. Tanno and S. Kishi, "Optical coherence tomographic imaging and clinical diagnosis," Medical Imaging Technology, vol. 17, no. 1, pp. 3-10, 1999.

143. J. Larsson, K. Holm, and M. Lövestam-Adrian, "The presence of an operculum verified by optical coherence tomography and other prognostic factors in macular hole surgery," Acta Ophthalmol. Scan., vol. 84, no. 3, pp. 301-304, 2006.

144. P. K. Kaiser, B. A. Blodi, H. Shapiro, and N. R. Acharya, "Angiographic and optical coherence tomographic results of the marina study of ranibizumab in neovascular age-related macular degeneration," Ophthalmology, vol. 114, no. 10, pp. 1868-1875, 2007.

145. O. Tan, G. Li, A. T.-H. Lu, R. Varma, and D. Huang, "Mapping of macular substructures with optical coherence tomography for glaucoma diagnosis," Ophthalmology, vol. 115, no. 6, pp. 949-956, 2008.

146. W. Soliman, B. Sander, K. A. E.-N. Soliman, S. Yehya, M. S. A. Rahamn, and M. Larsen, "The predictive value of optical coherence tomography after grid laser photocoagulation for diffuse diabetic macular oedema," Acta Ophthalmol., vol. 86, no. 3, pp. 284-291, 2008.

147. D. Gaucher, C. Sebah, A. Erginay, B. Haouchine, R. Tadayoni, A. Gaudric, and P. Massin, "Optical coherence tomography features during the evolution of serous retinal detachment in patients with diabetic macular edema," Am. J. Ophthalmol., vol. 145, no. 2, pp. 289296, 2008.

148. M. E. van Velthoven, D. J. Faber, F. D. Verbraak, T. G. van Leeuwen, and M. D. de Smet, "Recent developments in optical coherence tomography for imaging the retina," Prog. Retin. Eye Res., vol. 26, no. 1, pp. 57-77, 2007.

149. W. Drexler and J. G. Fujimoto, "State-of-the-art retinal optical coherence tomography," Prog. Retin. Eye Res., vol. 27 , no. 1 , pp. $45-88,2008$.

150. "Carl Zeiss Meditec delivers key technological advances in optical coherence tomography." www.medicalnewstoday.com, Apr 7 2010. Accessed 20 Nov 2010.

151. T. S. Chang, N. M. Bressler, J. T. Fine, C. W. Dolan, J. Ward, T. R. Klesert, and M. S. Group, "Improved vision-related function after ranibizumab treatment of neovascular age-related macular degeneration - results of a randomized clinical trial," Arch. Ophthalmol., vol. 125 , no. 11 , pp. 1460-1469, 2007.

152. D. M. Brown and C. D. Regillo, "Anti-VEGF agents in the treatment of neovascular age-related macular degeneration: Applying clinical trial results to the treatment of everyday patients," Am. J. Ophthalmol., vol. 144, no. 4, pp. 627-637.e2, 2007.

153. P. Jeppesen, S. T. Knudsen, P. L. Poulsen, C. E. Mogensen, O. Schmitz, and T. Bek, "Response of retinal arteriole diameter to increased blood pressure during acute hyperglycaemia," Acta Ophthalmol. Scan., vol. 85 , no. 3 , pp. $280-286,2007$.

154. M. Bolz, M. Ritter, M. Schneider, C. Simader, C. Scholda, and U. Schmidt-Erfurth, "A systematic correlation of angiography and high-resolution optical co- herence tomography in diabetic macular edema," Ophthalmology, vol. 116, no. 1, pp. 66-72, 2009.

155. J. Gyatsho, S. Kaushik, A. Gupta, S. Pandav, and J. Ram, "Retinal nerve fiber layer thickness in normal, ocular hypertensive, and glaucomatous indian eyes: An optical coherence tomography study," J. Glaucoma, vol. 17 , no. 2, pp. 122-127, 2008.

156. J. L. Hougaard, A. Heijl, and B. Bengtsson, "Glaucoma detection using different stratus optical coherence tomography protocols," Acta Ophthalmol. Scan., vol. 85, no. 3, pp. 251-256, 2007.

157. S. Li, X. Wang, S. Li, G. Wu, and N. Wang, "Evaluation of optic nerve head and retinal nerve fiber layer in early and advance glaucoma using frequency-domain optical coherence tomography," Graef. Arch. Clin. Exp., vol. 248 , no. 3, pp. 429-434, 2010.

158. C. K. S. Leung, S. Lam, R. N. Weinreb, S. Liu, C. Ye, L. Liu, J. He, G. W. K. Lai, T. Li, and D. S. C. Lam, "Retinal nerve fiber layer imaging with spectral-domain optical coherence tomography analysis of the retinal nerve fiber layer map for glaucoma detection," Ophthalmology, vol. 117, no. 9, pp. 1684-1691, 2010.

159. I. Kovacs, M. Ferencz, J. Nemes, G. Somfai, G. Salacz, and Z. Recsan, "Intraocular lens power calculation for combined cataract surgery, vitrectomy and peeling of epiretinal membranes for macular oedema," Acta Ophthalmol. Scan., vol. 85, no. 1, pp. 88-91, 2007.

160. M. Doors, T. T. J. M. Berendschot, J. de Brabander, C. A. B. Webers, and R. M. M. A. Nuijts, "Value of optical coherence tomography for anterior segment surgery," J. Cataract Refr. Surg., vol. 36, no. 7, pp. 1213-1229, 2010.

161. M. Kalev-Landoy, A. C. Day, M. F. Cordeiro, and C. Migdal, "Optical coherence tomography in anterior segment imaging," Acta Ophthalmol. Scan., vol. 85, no. 4, pp. 427-430, 2007.

162. T. C. Chen, B. Cense, B. H. Park, M. C. Pierce, and J. F. de Boer, "Polarization sensitive optical coherence tomography measurement of thickness and birefringence of healthy retinal nerve fiber layer tissue," Invest. Ophth. Vis. Sci., vol. 45, no. Suppl. 2, p. U114, 2004.

163. B. Baumann, E. Götzinger, M. Pircher, H. Sattmann, C. Schütze, F. Schlanitz, C. Ahlers, U. Schmidt-Erfurth, and C. K. Hitzenberger, "Segmentation and quantification of retinal lesions in age-related macular degeneration using polarization-sensitive optical coherence tomography," J. Biomed. Opt., vol. 15, no. 6, p. 061704, 2010.

164. S. Michels, M. Pircher, W. Geitzenauer, C. Simader, E. Götzinger, O. Findl, U. Schmidt-Erfurth, and C. K. Hitzenberger, "Value of polarisation-sensitive optical coherence tomography in diseases affecting the retinal pigment epithelium," Brit. J. Ophthalmol., vol. 92, no. 2, pp. 204-209, 2008.

165. S. Yazdanfar, A. M. Rollins, and J. A. Izatt, "Imaging and velocimetry of the human retinal circulation with color doppler optical coherence tomography," Opt. Lett., vol. 25, pp. 1448-1450, Oct 2000.

166. S. Makita, Y. Hong, M. Yamanari, T. Yatagai, and Y. Yasuno, "Optical coherence angiography," Opt. Express, vol. 14, pp. 7821-7840, Aug 2006.

167. V. J. Srinivasan, Y. Chen, J. S. Duker, and J. G. Fujimoto, "In vivo functional imaging of intrinsic scattering changes in the human retina with high-speed ultrahigh resolution OCT," Opt. Express, vol. 17, pp. 3861-3877, Mar 2009. 
168. B. Hermann, E. J. Fernández, A. Unterhuber, H. Sattmann, A. F. Fercher, W. Drexler, P. M. Prieto, and P. Artal, "Adaptive-optics ultrahigh-resolution optical coherence tomography," Opt. Lett., vol. 29, pp. 2142-2144, Sep 2004.

169. R. Zawadzki, S. Jones, S. Olivier, M. Zhao, B. Bower, J. Izatt, S. Choi, S. Laut, and J. Werner, "Adaptiveoptics optical coherence tomography for high-resolution and high-speed 3D retinal in vivo imaging," Opt. Express, vol. 13, pp. 8532-8546, Oct 2005.

170. W. Drexler, U. Morgner, R. K. Ghanta, F. X. Kärtner, J. S. Schuman, and J. G. Fujimoto, "Ultrahighresolution ophthalmic optical coherence tomography.," Nat. Med., vol. 7, no. 4, pp. 502-507, 2001.

171. Y. Yasuno, Y. Hong, S. Makita, M. Yamanari, M. Akiba, M. Miura, and T. Yatagai, "In vivo high-contrast imaging of deep posterior eye by $1-\mu \mathrm{m}$ swept source optical coherence tomography and scattering optical coherence angiography," Opt. Express, vol. 15, pp. 6121-6139, May 2007.

172. D. X. Hammer, M. Mujat, N. V. Iftimia, N. Lue, and R. D. Ferguson, "Multimodal adaptive optics for depthenhanced high-resolution ophthalmic imaging," Proc. SPIE, vol. 7550, no. 1, pp. 755011-12, 2010.

173. U. Schmidt-Erfurth, R. A. Leitgeb, S. Michels, B. Povazay, S. Sacu, B. Hermann, C. Ahlers, H. Sattmann, C. Scholda, A. F. Fercher, and W. Drexler, "Threedimensional ultrahigh-resolution optical coherence tomography of macular diseases," Invest. Ophth. Vis. Sci., vol. 46, no. 9, pp. 3393-3402, 2005.

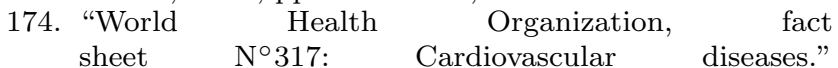
www.who.int/mediacentre/factsheets/fs317/en/. Accessed 19 Nov 2010.

175. R. Virmani, F. D. Kolodgie, A. P. Burke, A. Farb, and S. M. Schwartz, "Lessons from sudden coronary death: A comprehensive morphological classification scheme for atherosclerotic lesions," Arterioscl. Throm. Vas., vol. 20 , no. 5 , pp. $1262-1275,2000$.

176. I.-K. Jang, B. E. Bouma, D.-H. Kang, S.-J. Park, S.-W. Park, K.-B. Seung, K.-B. Choi, M. Shishkov, K. Schlendorf, E. Pomerantsev, S. L. Houser, H. T. Aretz, and G. J. Tearney, "Visualization of coronary atherosclerotic plaques in patients using optical coherence tomography: Comparison with intravascular ultrasound," $J$. Am. Coll. Cardiol., vol. 39, no. 4, pp. 604-609, 2002.

177. A. F. Low, G. J. Tearney, B. E. Bouma, and I.-K. Jang, "Technology insight: optical coherence tomography - current status and future development," Nat. Clin. Pract. Card., pp. 154-162, 2006.

178. H. Yabushita, B. E. Bouma, S. L. Houser, H. T. Aretz, I.-K. Jang, K. H. Schlendorf, C. R. Kauffman, M. Shishkov, D.-H. Kang, E. F. Halpern, and G. J. Tearney, "Characterization of human atherosclerosis by optical coherence tomography," Circulation, vol. 106, no. 13, pp. 1640-1645, 2002.

179. G. J. Tearney, I.-K. Jang, and B. E. Bouma, "Optical coherence tomography for imaging the vulnerable plaque," J. Biomed. Opt., vol. 11, no. 2, p. 021002, 2006.

180. M. E. Brezinski, "Applications of optical coherence tomography to cardiac and musculoskeletal diseases: bench to bedside?," J. Biomed. Opt., vol. 12, no. 5, p. $051705,2007$.

181. I.-K. Jang, G. J. Tearney, B. MacNeill, M. Takano, F. Moselewski, N. Iftima, M. Shishkov, S. Houser, H. T. Aretz, E. F. Halpern, and B. E. Bouma, "In vivo characterization of coronary atherosclerotic plaque by use of optical coherence tomography," Circulation, vol. 111, no. 12 , pp. 1551-1555, 2005.

182. T. Kume, T. Akasaka, T. Kawamoto, H. Okura, N. Watanabe, E. Toyota, Y. Neishi, R. Sukmawan, Y. Sadahira, and K. Yoshida, "Measurement of the thickness of the fibrous cap by optical coherence tomography," Am. Heart J., vol. 152, no. 4, pp. 755.e1-e4, 2006.

183. G. J. Tearney, H. Yabushita, S. L. Houser, H. T. Aretz, I.-K. Jang, K. H. Schlendorf, C. R. Kauffman, M. Shishkov, E. F. Halpern, and B. E. Bouma, "Quantification of macrophage content in atherosclerotic plaques by optical coherence tomography.," Circulation, vol. 107, no. 1, pp. 113-119, 2003.

184. S. K. Nadkarni, M. C. Pierce, B. H. Park, J. F. de Boer, P. Whittaker, B. E. Bouma, J. E. Bressner, E. Halpern, S. L. Houser, and G. J. Tearney, "Measurement of collagen and smooth muscle cell content in atherosclerotic plaques using polarization-sensitive optical coherence tomography," J. Am. Coll. Cardiol., vol. 49, no. 13, pp. 1474-1481, 2007.

185. O. C. Raffel, F. M. Merchant, G. J. Tearney, S. Chia, D. D. Gauthier, E. Pomerantsev, K. Mizuno, B. E. Bouma, and I.-K. Jang, "In vivo association between positive coronary artery remodelling and coronary plaque characteristics assessed by intravascular optical coherence tomography," Eur. Heart J., vol. 29, no. 14, pp. 1721-1728, 2008.

186. Q. X. Li, Q. Q. Fu, S. W. Shi, Y. F. Wang, J. J. Xie, X. Yu, X. Cheng, and Y. H. Liao, "Relationship between plasma inflammatory markers and plaque fibrous cap thickness determined by intravascular optical coherence tomography," Heart, vol. 96, no. 3, pp. 196-201, 2010.

187. R. Yamada, H. Okura, T. Kume, K. Saito, Y. Miyamoto, K. Imai, T. Tsuchiya, T. Maehama, N. Okahashi, K. Obase, A. Hayashida, Y. Neishi, T. Kawamoto, and K. Yoshida, "Relationship between arterial and fibrous cap remodeling," Circ. Cardiovasc. Interv., vol. 3, no. 5, pp. 484-490, 2010.

188. "Evaluation of statin-induced lipid-rich plaque progression by optical coherence tomography (OCT) combined with intravascular ultrasound (IVUS)." http://clinicaltrials.gov/ct2/show/study/NCT01023607, Dec 1 2009. Accessed 22 Mar 2011.

189. L. J. Diaz-Sandoval, B. E. Bouma, G. J. Tearney, and I.-K. Jang, "Optical coherence tomography as a tool for percutaneous coronary interventions," Catheter. Cardio. Inte., vol. 65, no. 4, pp. 492-496, 2005.

190. N. Gonzalo, P. W. Serruys, T. Okamura, Z. J. Shen, Y. Onuma, H. M. Garcia-Garcia, G. Sarno, C. Schultz, R. J. van Geuns, J. Ligthart, and E. Regar, "Optical coherence tomography assessment of the acute effects of stent implantation on the vessel wall: a systematic quantitative approach," Heart, vol. 95, no. 23, pp. 19131919, 2009.

191. A. Murata, D. Wallace-Bradley, A. Tellez, C. Alviar, M. Aboodi, A. Sheehy, L. Coleman, L. Perkins, G. Nakazawa, G. Mintz, G. L. Kaluza, R. Virmani, and J. F. Granada, "Accuracy of optical coherence tomography in the evaluation of neointimal coverage after stent implantation," J. Am. Coll. Cardiol. Img., vol. 3, no. 1, pp. 76-84, 2010.

192. Y. Ozaki, M. Okumura, T. F. Ismail, H. Naruse, K. Hattori, S. Kan, M. Ishikawa, T. Kawai, Y. Takagi, J. Ishii, F. Prati, and P. W. Serruys, "The fate of incomplete stent apposition with drug-eluting stents: an optical co- 
herence tomography-based natural history study," Eur. Heart J., vol. 31, no. 12, pp. 1470-1476, 2010.

193. G. Guagliumi and V. Sirbu, "Optical coherence tomography: High resolution intravascular imaging to evaluate vascular healing after coronary stenting," Catheter. Cardio. Inte., vol. 72, no. 2, p. 237, 2008.

194. B. E. Bouma, G. J. Tearney, H. Yabushita, M. Shishkov, C. R. Kauffman, D. DeJoseph Gauthier, B. D. MacNeill, S. L. Houser, H. T. Aretz, E. F. Halpern, and I.-K. Jang, "Evaluation of intracoronary stenting by intravascular optical coherence tomography," Heart, vol. 89, no. 3, pp. 317-320, 2003.

195. S. H. Yun, G. J. Tearney, B. J. Vakoc, M. Shishkov, W. Y. Oh, A. E. Desjardins, M. J. Suter, R. C. Chan, J. A. Evans, I.-K. Jang, N. S. Nishioka, J. F. de Boer, and B. E. Bouma, "Comprehensive volumetric optical microscopy in vivo.," Nat. Med., vol. 12, no. 12, pp. 1429-1433, 2006.

196. J. G. Fujimoto, S. A. Boppart, G. J. Tearney, B. E. Bouma, C. Pitris, and M. E. Brezinski, "High resolution in vivo intra-arterial imaging with optical coherence tomography," Heart, vol. 82, no. 2, pp. 128-133, 1999.

197. F. Prati, M. Cera, V. Ramazzotti, F. Imola, R. Giudice, and M. Albertucci, "Safety and feasibility of a new non-occlusive technique for facilitated intracoronary optical coherence tomography (OCT) acquisition in various clinical and anatomical scenarios," EuroIntervention, vol. 3, pp. 365 - 70, 2007. PubMed PMID: 19737719.

198. T. Yamaguchi, M. Terashima, T. Akasaka, T. Hayashi, K. Mizuno, T. Muramatsu, M. Nakamura, S. Nakamura, S. Saito, M. Takano, T. Takayama, J. Yoshikawa, and T. Suzuki, "Safety and feasibility of an intravascular optical coherence tomography image wire system in the clinical setting," Am. J. Cardiol., vol. 101, no. 5, pp. 562-567, 2008.

199. M. E. Brezinski, K. Saunders, C. Jesser, X. Li, and J. G. Fujimoto, "Index matching to improve optical coherence tomography imaging through blood," Circulation, vol. 103, no. 15, pp. 1999-2003, 2001.

200. J. W. Villard, M. D. Feldman, J. Kim, T. E. Milner, and G. L. Freeman, "Use of a blood substitute to determine instantaneous murine right ventricular thickening with optical coherence tomography," Circulation, vol. 105, no. 15 , pp. $1843-1849,2002$.

201. K. C. Hoang, A. Edris, J. Su, D. S. Mukai, S. Mahon, A. D. Petrov, M. Kern, C. Ashan, Z. Chen, B. J. Tromberg, J. Narula, and M. Brenner, "Use of an oxygen-carrying blood substitute to improve intravascular optical coherence tomography imaging," J. Biomed. Opt., vol. 14, no. 3, p. 034028, 2009.

202. F. Prati, E. Regar, G. S. Mintz, E. Arbustini, C. Di Mario, I.-K. Jang, T. Akasaka, M. Costa, G. Guagliumi, E. Grube, Y. Ozaki, F. Pinto, and P. W. J. Serruys, "Expert review document on methodology, terminology, and clinical applications of optical coherence tomography: physical principles, methodology of image acquisition, and clinical application for assessment of coronary arteries and atherosclerosis," Eur. Heart J., vol. 31, no. 4, pp. 401-415, 2010.

203. M. J. Suter, G. J. Tearney, W.-Y. Oh, and B. E. Bouma, "Progress in intracoronary optical coherence tomography," IEEE J. Sel. Top. Quant., vol. 16, no. 4, pp. 706$714,2010$.

204. R. Steiner, K. Kunzi-Rapp, and K. ScharffetterKochanek, "Optical coherence tomography: Clinical ap- plications in dermatology," Med. Laser Appl., vol. 18, no. 3, pp. 249-259, 2003.

205. M. Mogensen, G. B. E. Jemec, L. Thrane, T. M. Jørgensen, and P. E. Andersen, "OCT imaging of skin cancer and other dermatological diseases," J. Biophotonics, vol. 2, no. 6-7, pp. 442-451, 2009.

206. M. Mogensen, B. M. Nürnberg, J. L. Forman, J. B. Thomsen, L. Thrane, and G. B. E. Jemec, "In vivo thickness measurement of basal cell carcinoma and actinic keratosis with optical coherence tomography and 20-MHz ultrasound," Brit. J. Dermatol., vol. 160, no. 5, pp. 1026-1033, 2009.

207. M. Mogensen, H. A. Morsy, L. Thrane, and G. B. E. Jemec, "Morphology and epidermal thickness of normal skin imaged by optical coherence tomography," Dermatology, vol. 217 , no. 1 , pp. 14-20, 2008.

208. A. Alex, B. Považay, B. Hofer, S. Popov, C. Glittenberg, S. Binder, and W. Drexler, "Multispectral in vivo three-dimensional optical coherence tomography of human skin," J. Biomed. Opt., vol. 15, no. 2, p. 026025, 2010.

209. J. Welzel, "Optical coherence tomography in dermatology: A review," Skin Res. Technol., vol. 7, no. 1, pp. 19, 2001.

210. T. Gambichler, P. Regeniter, F. G. Bechara, A. Orlikov, R. Vasa, G. Moussa, M. Stücker, P. Altmeyer, and K. Hoffmann, "Characterization of benign and malignant melanocytic skin lesions using optical coherence tomography in vivo," J. Am. Acad. Dermatol., vol. 57, no. 4 , pp. $629-637,2007$.

211. T. Gambichler, J. Huyn, N. S. Tomi, G. Moussa, C. Moll, A. Sommer, P. Altmeyer, and K. Hoffmann, "A comparative pilot study on ultraviolet-induced skin changes assessed by noninvasive imaging techniques in vivo," Photochem. Photobiol., vol. 82, no. 4, pp. 1103$1107,2006$.

212. T. Gambichler, A. Orlikov, R. Vasa, G. Moussa, K. Hoffmann, M. Stücker, P. Altmeyer, and F. G. Bechara, "In vivo optical coherence tomography of basal cell carcinoma," J. Dermatol. Sci., vol. 45, no. 3, pp. 167-173, 2007.

213. J. M. Olmedo, K. E. Warschaw, J. M. Schmitt, and D. L. Swanson, "Optical coherence tomography for the characterization of basal cell carcinoma in vivo: A pilot study," J. Am. Acad. Dermatol., vol. 55, no. 3, pp. 408$412,2006$.

214. M. Khandwala, B. R. Penmetsa, S. Dey, J. B. Schofield, C. A. Jones, and A. Podoleanu, "Imaging of periocular basal cell carcinoma using en face optical coherence tomography: a pilot study," Brit. J. Ophthalmol., vol. 94, no. 10 , pp. $1332-1336,2010$.

215. V. R. Korde, G. T. Bonnema, W. Xu, C. Krishnamurthy, J. Ranger-Moore, K. Saboda, L. D. Slayton, S. J. Salasche, J. A. Warneke, D. S. Alberts, and J. K. Barton, "Using optical coherence tomography to evaluate skin sun damage and precancer," Las. Surg. Med., vol. 39, no. 9, pp. 687-695, 2007.

216. T. M. Jørgensen, A. Tycho, M. Mogensen, G. B. E. Jemec, and P. Bjerring, "Machine-learning classification of non-melanoma skin cancers from image features obtained by optical coherence tomography," Skin Res. Technol., vol. 14, no. 3, pp. 364-369, 2008.

217. M. Mogensen, T. M. Jørgensen, L. Thrane, B. M. Nürnberg, and G. B. E. Jemec, "Improved quality of optical coherence tomography imaging of basal cell carcinomas using speckle reduction," Exp. Dermatol., vol. 19, no. 8, pp. e293-e295, 2010. 
218. J. Strasswimmer, M. C. Pierce, B. H. Park, V. Neel, and J. F. de Boer, "Polarization-sensitive optical coherence tomography of invasive basal cell carcinoma," $J$. Biomed. Opt., vol. 9, no. 2, pp. 292-298, 2004.

219. M. Mogensen, T. M. Jørgensen, B. M. Nünberg, H. A. Morsy, J. B. Thomsen, L. Thrane, and G. B. E. Jemec, "Assessment of optical coherence tomography imaging in the diagnosis of non-melanoma skin cancer and benign lesions versus normal skin: Observer-blinded evaluation by dermatologists and pathologists," Dermatol. Surg., vol. 35, no. 6, pp. 965-972, 2009.

220. "Michelson Diagnostics awarded CE mark." www.mdltd.co.uk/news-and-media.html, Sep 17 2009. Accessed 1 Dec 2010.

221. "VivoSight OCT scanner receives FDA 510(k) clearance." www.md-ltd.co.uk/news-and-media.html, Jan 15 2010. Accessed 1 Dec 2010.

222. J. Hewett, "OCT skin cancer trials to expand next year." http://optics.org/news/1/6/16, Nov 15 2010. Accessed 1 Dec 2010.

223. J. G. Fujimoto, M. E. Brezinski, G. J. Tearney, S. A. Boppart, B. Bouma, M. R. Hee, J. F. Southern, and E. A. Swanson, "Optical biopsy and imaging using optical coherence tomography," Nat. Med., vol. 1, no. 9, pp. 970-972, 1995.

224. J. A. Evans, J. M. Poneros, B. E. Bouma, J. Bressner, E. F. Halpern, M. Shishkov, G. Y. Lauwers, M. Minokenudson, N. S. Nishioka, and G. J. Tearney, "Optical coherence tomography to identify intramucosal carcinoma and high-grade dysplasia in Barrett's esophagus," Clin. Gastroenterol. H., vol. 4, no. 1, p. 38, 2006.

225. Y. Chen, A. D. Aguirre, P. L. Hsiung, S. Desai, P. R. Herz, M. Pedrosa, Q. Huang, M. Figueiredo, S.-W. Huang, A. Koski, J. M. Schmitt, J. G. Fujimoto, and H. Mashimo, "Ultrahigh resolution optical coherence tomography of Barrett's esophagus: preliminary descriptive clinical study correlating images with histology," Endoscopy, vol. 39, no. 7, p. 599, 2007.

226. R. K. Wang, J. B. Elder, and V. Smith, "High resolution imaging of colonic mucosa using optical coherence tomography," Proc. SPIE, vol. 4251, pp. 242-246, 2001.

227. M. Tsuboi, A. Hayashi, N. Ikeda, H. Honda, Y. Kato, S. Ichinose, and H. Kato, "Optical coherence tomography in the diagnosis of bronchial lesions," Lung Cancer, vol. 49, no. 3, pp. 387-394, 2005.

228. C. A. Jesser, S. A. Boppart, C. Pitris, D. L. Stamper, G. P. Nielsen, M. E. Brezinski, and J. G. Fujimoto, "High resolution imaging of transitional cell carcinoma with optical coherence tomography: feasibility for the evaluation of bladder pathology," Brit. J. Radiol., vol. 72 , no. 864 , pp. $1170-1176,1999$.

229. B. A. Standish, X. Jin, J. Smolen, A. Mariampillai, N. R. Munce, B. C. Wilson, I. A. Vitkin, and V. X. D. Yang, "Interstitial Doppler optical coherence tomography monitors microvascular changes during photodynamic therapy in a Dunning prostate model under varying treatment conditions," J. Biomed. Opt., vol. 12, no. 3, p. 034022, 2007.

230. S. A. Boppart, W. Luo, D. L. Marks, and K. W. Singletary, "Optical coherence tomography: Feasibility for basic research and image-guided surgery of breast cancer," Breast Cancer Res. Tr., vol. 84, no. 2, pp. 85-97, 2004.

231. S. A. Boppart, B. E. Bouma, C. Pitris, G. J. Tearney, J. G. Fujimoto, and M. E. Brezinski, "Forwardimaging instruments for optical coherence tomography," Opt. Lett., vol. 22, pp. 1618-1620, Nov 1997.
232. X. Li, S. Martin, C. Pitris, R. Ghanta, D. Stamper, M. Harman, J. Fujimoto, and M. Brezinski, "Highresolution optical coherence tomographic imaging of osteoarthritic cartilage during open knee surgery," Arthritis Res. Ther., vol. 7, no. 2, pp. R318-323, 2005.

233. K. Zheng, S. D. Martin, C. H. Rashidifard, B. Liu, and M. E. Brezinski, "In vivo micron-scale arthroscopic imaging of human knee osteoarthritis with optical coherence tomography: comparison with magnetic resonance imaging and arthroscopy.," Am. J. Orthop., vol. 39, no. 3, pp. $122-125,2010$.

234. C. R. Chu, N. J. Izzo, J. J. Irrgang, M. Ferretti, and R. K. Studer, "Clinical diagnosis of potentially treatable early articular cartilage degeneration using optical coherence tomography," J. Biomed. Opt., vol. 12, no. 5, p. 051703, 2007.

235. C. H.-Y. Ling, A. Pozzi, K. M. Thieman, C. A. Tonks, S. Guo, H. Xie, and M. Horodyski, "The potential of optical coherence tomography for diagnosing meniscal pathology," Meas. Sci. Technol., vol. 21, p. 045801, apr 2010.

236. R. A. McLaughlin, L. Scolaro, P. Robbins, S. Hamza, C. Saunders, and D. D. Sampson, "Imaging of human lymph nodes using optical coherence tomography: Potential for staging cancer," Cancer Res., vol. 70, no. 7, pp. 2579-2584, 2010.

237. F. T. Nguyen, A. M. Zysk, E. J. Chaney, S. G. Adie, J. G. Kotynek, U. J. Oliphant, F. J. Bellafiore, K. M. Rowland, P. A. Johnson, and S. A. Boppart, "Optical coherence tomography: The intraoperative assessment of lymph nodes in breast cancer," IEEE Eng. Med. Biol., vol. 29, no. 2, pp. 63-70, 2010.

238. S. A. Boppart, M. E. Brezinski, B. E. Bouma, G. J. Tearney, and J. G. Fujimoto, "Investigation of developing embryonic morphology using optical coherence tomography," Dev. Biol., vol. 177, no. 1, pp. 54-63, 1996.

239. B. B. Keller, Development of cardiovascular systems: molecules to organisms, ch. 7, pp. 65-91. Cambridge University Press, 1997.

240. J. I. E. Hoffman, "Incidence of congenital heart disease: I. postnatal incidence," Pediatr. Cardiol., vol. 16, no. 3, pp. 103-113, 1995.

241. T. M. Yelbuz, M. A. Choma, L. Thrane, M. L. Kirby, and J. A. Izatt, "Optical coherence tomography: A new high-resolution imaging technology to study cardiac development in chick embryos," Circulation, vol. 106, no. 22 , p. 2771, 2002.

242. S. A. Boppart, G. J. Tearney, B. E. Bouma, J. F. Southern, M. E. Brezinski, and J. G. Fujimoto, "Noninvasive assessment of the developing xenopus cardiovascular system using optical coherence tomography," $P$. Natl. Acad. Sci. USA, vol. 94, no. 9, pp. 4256-4261, 1997.

243. A. Mariampillai, B. A. Standish, N. R. Munce, C. Randall, G. Liu, J. Y. Jiang, A. E. Cable, I. A. Vitkin, and V. X. D. Yang, "Doppler optical cardiogram gated 2D color flow imaging at $1000 \mathrm{fps}$ and $4 \mathrm{D}$ in vivo visualization of embryonic heart at $45 \mathrm{fps}$ on a swept source OCT system," Opt. Express, vol. 15, pp. 1627-1638, Feb 2007.

244. M. W. Jenkins, D. C. Adler, M. Gargesha, R. Huber, F. Rothenberg, J. Belding, M. Watanabe, D. L. Wilson, J. G. Fujimoto, and A. M. Rollins, "Ultrahigh-speed optical coherence tomography imaging and visualization of the embryonic avian heart using a buffered fourier domain mode locked laser," Opt. Express, vol. 15, no. 10, pp. 6251-6267, 2007. 
245. W. Luo, D. L. Marks, T. S. Ralston, and S. A. Boppart, "Three-dimensional optical coherence tomography of the embryonic murine cardiovascular system," J. Biomed. Opt., vol. 11, no. 2, pp. 021014-8, 2006.

246. K. Norozi, L. Thrane, J. Männer, F. Pedersen, I. Wolf, S. Mottl-Link, H.-P. Meinzer, A. Wessel, and T. M. Yelbuz, "In vivo visualisation of coronary artery development by high-resolution optical coherence tomography," Heart, vol. 94, no. 2, p. 130, 2008.

247. J. Männer, L. Thrane, K. Norozi, and T. M. Yelbuz, "In vivo imaging of the cyclic changes in cross-sectional shape of the ventricular segment of pulsating embryonic chick hearts at stages 14 to 17: A contribution to the understanding of the ontogenesis of cardiac pumping function," Dev. Dynam., vol. 238, no. 12, pp. 3273-3284, 2009.

248. V. X. D. Yang, M. Gordon, E. Seng-Yue, S. Lo, B. Qi, J. Pekar, A. Mok, B. Wilson, and I. Vitkin, "High speed, wide velocity dynamic range Doppler optical coherence tomography (part II): Imaging in vivo cardiac dynamics of xenopus laevis," Opt. Express, vol. 11, pp. 1650-1658, Jul 2003.

249. I. V. Larina, N. Sudheendran, M. Ghosn, J. Jiang, A. Cable, K. V. Larin, and M. E. Dickinson, "Live imaging of blood flow in mammalian embryos using Doppler swept-source optical coherence tomography," $J$. Biomed. Opt., vol. 13, no. 6, p. 060506, 2008.

250. L. Thrane, H. E. Larsen, K. Norozi, F. Pedersen, J. B. Thomsen, M. Trojer, and T. M. Yelbuz, "Field programmable gate-array-based real-time optical Doppler tomography system for in vivo imaging of cardiac dynamics in the chick embryo," Opt. Eng., vol. 48, no. 2, pp. 023201-13, 2009.

251. S.-J. Lin, S.-H. Jee, C.-J. Kuo, R.-J. Wu, W.-C. Lin, J.S. Chen, Y.-H. Liao, C.-J. Hsu, T.-F. Tsai, Y.-F. Chen, and C.-Y. Dong, "Discrimination of basal cell carcinoma from normal dermal stroma by quantitative multiphoton imaging," Opt. Lett., vol. 31, pp. 2756-2758, Sep 2006.

252. K. König, M. Speicher, R. Bückle, J. Reckfort, G. McKenzie, J. Welzel, M. J. Koehler, P. Elsner, and M. Kaatz, "Clinical optical coherence tomography combined with multiphoton tomography of patients with skin diseases," J. Biophotonics, vol. 2, no. 6-7, pp. 389$397,2009$.

253. C. Vinegoni, T. Ralston, W. Tan, W. Luo, D. L. Marks, and S. A. Boppart, "Integrated structural and functional optical imaging combining spectral-domain optical coherence and multiphoton microscopy," Appl. Phys. Lett., vol. 88, no. 5, pp. 1-3, 2006.

254. E. E. Lawson, B. W. Barry, A. C. Williams, and H. G. M. Edwards, "Biomedical applications of Raman spectroscopy," J. Raman Spectrosc., vol. 28, no. 2-3, pp. 111-117, 1997.

255. D. I. Ellis and R. Goodacre, "Metabolic fingerprinting in disease diagnosis: biomedical applications of infrared and Raman spectroscopy," Analyst, vol. 131, no. 8, pp. 875-885, 2006.

256. P. R. T. Jess, M. Mazilu, K. Dholakia, A. C. Riches, and C. S. Herrington, "Optical detection and grading of lung neoplasia by Raman microspectroscopy," Int. J. Cancer, vol. 124, no. 2, pp. 376-380, 2009.

257. J. Mo, W. Zheng, J. J. H. Low, J. Ng, A. Ilancheran, and Z. Huang, "High wavenumber Raman spectroscopy for in vivo detection of cervical dysplasia," Anal. Chem., vol. 81, no. 21, pp. 8908-8915, 2009. PMID: 19817391.

258. C. A. Patil, N. Bosschaart, M. D. Keller, T. G. van Leeuwen, and A. Mahadevan-Jansen, "Combined Ra- man spectroscopy and optical coherence tomography device for tissue characterization," Opt. Lett., vol. 33, pp. 1135-1137, May 2008.

259. C. A. Patil, H. Kirshnamoorthi, D. L. Ellis, T. G. van Leeuwen, and A. Mahadevan-Jansen, "A clinical instrument for combined Raman spectroscopy-optical coherence tomography of skin cancers," Laser Surg. Med., vol. 43, no. 2, pp. 143-151, 2011.

260. R. H. Webb and G. W. Hughes, "Scanning laser ophthalmoscope," IEEE T. Biomed. Eng., vol. BME-28, no. 7, pp. 488-492, 1981.

261. Heidelberg Engineering, Inc., Spectralis $H R A+O C T$, 2010. data sheet 1758 .

262. H.-M. Helb, P. Charbel Issa, S. Fleckenstein, Monikaand Schmitz-Valckenberg, H. P. N. Scholl, C. H. Meyer, N. Eter, and F. G. Holz, "Clinical evaluation of simultaneous confocal scanning laser ophthalmoscopy imaging combined with high-resolution, spectral-domain optical coherence tomography.," Acta Ophthalmol., vol. 88, no. 8 , pp. $842-849,2010$.

263. M. Xu and L. V. Wang, "Photoacoustic imaging in biomedicine," Rev. Sci. Instrum., vol. 77, no. 4, p. $41101,2006$.

264. L. Li, K. Maslov, G. Ku, and L. V. Wang, "Threedimensional combined photoacoustic and optical coherence microscopy for in vivo microcirculation studies," Opt. Express, vol. 17, pp. 16450-16455, Sep 2009.

265. E. Z. Zhang, J. Laufer, B. Považay, A. Alex, B. Hofer, W. Drexler, and P. Beard, "Multimodal simultaneous photoacoustic tomography, optical resolution microscopy, and OCT system," Proc. SPIE, vol. 7564, p. $75640 \mathrm{U}, 2010$. 